\title{
Structural and Vibrational Study On the Acid, Hexa-Hydrated and Anhydrous Trisodic Salts of Antiviral Drug Foscarnet
}

\author{
Maximiliano A Iramain and Silvia A Brandán* \\ Faculty of Biochemistry, Chemistry and Pharmacy, National University of Tucumán, Ayacucho, Tucumán, Argentina
}

Received: 眥 May 01, 2018; Published: 眥 May 09, 2018

*Corresponding author: Silvia A Brandán, Faculty of Biochemistry, Chemistry and Pharmacy, National University of Tucumán, Argentina

\begin{abstract}
The structural and vibrational properties of acid species, hexa-hydrated and anhydrous trisodic salts of antiviral drug foscarnet in gas phase and in aqueous solution have been studied in this work by using the hybrid B3LYP method with the 6-31G* and $6-311++G^{* *}$ basis sets. The properties in solution were carried out with the self consistent reaction force (SCRF) method by using the integral equation formalism variant polarised continuum (IEFPCM) and SD models while the complete vibrational assignments for those three species were performed in both media by using the experimental available infrared spectrum of hexa-hydrated trisodic salt and the scaled quantum mechanical force field (SQMFF) methodology. The natural bond orbital (NBO) studies suggest that the hexa-hydrated salt in solution is most stable than the anhydrous one in the same medium but in gas phases the anhydrous salt shows a higher stability in solution. The atoms in molecules (AIM) analyses have revealed the ionic characteristics of the 0--$\mathrm{Na}$ bonds in both salts supporting the higher stability of the hexa-hydrated salt in solution. The evaluation of the frontier orbitals show that the anhydrous salt is the most reactive species in solution, as supported by its higher solvation energy and volume variation. Apparently, the presences of phosphate group in foscarnet probably increase its activity when it is used as drug. The experimental infrared bands observed in the hexa-hydrated species at 1059 and $983 \mathrm{~cm}^{-1}$ are clearly attributed to the stretching modes of phosphate group while the strong bands at 1445 and $1333 \mathrm{~cm}^{-1}$ are associated to the stretching modes of carboxylate group. In addition, the force constants for the carboxylate and phosphate groups are reported.
\end{abstract}

Keywords: Foscarnet; Vibrational Spectra; Molecular Structure; Force Field; DFT Calculations

Abbreviations: SCRF: Self Consistent Reaction Force; IEFPCM: Integral Equation Formalism Variant Polarised Continuum; SQMFF: Scaled Quantum Mechanical Force Field; NBO: Natural Bond Orbital; AIM: Atoms In Molecules; HIV: Human Immunodeficiency Virus; PCM: Polarized Continuum Model; NPA: Atomic Natural Population; MK: Merz-Kollman; PED: Potential Energy Distribution Components; BO: Bond Orders; MEP: Molecular Electrostatic Potentials; AIM: Atoms in Molecules; RCPs: Ring Critical Point

\section{Introduction}

Foscarnet is an antiviral agent used in the treatment of human immunodeficiency virus (HIV) infections and of herpes viruses (HSV-1, HSV-2, VZV, CMV, etc.), as was reported from long time ago [1-4]. However, the continuous use of this drug in numerous patients can generate pathological micro calcifications in various tissues and, as a consequence different kinds of diseases can be found,

being among others, cancer and cardiovascular abnormalities including in patient's transplanted kidney produces nephro toxicity [5-13]. This later disease can be diagnosed analyzing carefully from a biopsy the crystal solid deposited in the sample by using different spectroscopic techniques, as reported in the literature [5-13]. Hence, the preparations of other derivatives of foscarnet are useful and important to design new drugs with the same biological activities 
but with fewer side effects [14-18]. Temperini et al. [19] have found that foscarnet also can acts as an activator/inhibitor of the metallo enzyme carbonic anhydrase and they have resolved the structure of this adduct by using X-ray diffraction, including the structure of foscarnet. Structurally, this drug is the trisodium phosphonoformate salt and, despite their very simple structure the conformers in gas phase only for the acid form of foscarnet were recently studied by Khalili et al. [20] from a theoretical point of view [20]. Thus, these authors have studied conformers, gas phase acidity and metal ion affinity with selected cations and alkaline earths by using DFT calculations but the trisodium phosphonoformate and their hexahydrated salts were not studied in that work. On the other hand, the Micro-Fourier Transform Infrared ( $\mu$ FTIR) and Raman spectres copies are very useful techniques to identify and analyze samples in different aggregation state in easy and quick form, such as biopsies and, in particular the presence of phosphate group in foscarnet [9-13]. Hence, the experimental infrared spectrum and imaging from Raman spectroscopy were reported by those authors but the structural properties and vibrational spectra of the trisodium phosphonoformate and their hexa-hydrated salts of foscarnet were no assigned so far. Hence, the aims of this work are:

a) To study the theoretical structures of the acid form of foscarnet and their two trisodium phosphonoformate and hexahydrated trisodic salts in gas phase and in aqueous solution in order to compute their structural, electronic, topological and vibrational properties,

b) To perform the complete vibrational analysis of the acid and their two salts in order to identify those species of foscarnet by using the vibrational spectroscopy.

For these purposes, theoretical calculations were performed for foscarnet in both media by using the hybrid B3LYP method and the $6-311++G^{* *}$ basis set $[21,22]$. Here, it is important to mention that the calculations for the trisodic salt with six implicit water molecules in both media were also considered because this salt is the form commercially available. In solution, the effect solvents were computed with the self consistent force field (SCRF) method by using the integral equation formalism variant polarised continuum model (IEFPCM) model and SD models in order to calculate their properties together with the solvation energy [23-25]. With the optimized structures of the acid and their salts in both media the harmonic frequencies were calculated in order to combine with the experimental available infrared spectrum and to perform the complete assignments of foscarnet in both media by using their corresponding force fields. To calculated the force fields the SQMFF methodology was employed together with the Molvib program and the corresponding normal internal coordinates [26,27]. Here, all properties were calculated in both media in order to compare with those obtained in gas phase. The predicted infrared and Raman spectra for the two salts of foscarnet were also reported together with the ultraviolet-visible spectra in aqueous solution. These results will permit that the different species of foscarnet can be easily identified by using the vibrational spectroscopy in gas and in aqueous solution phases. Besides, in order to understand why foscarnet is biologically active it is essential to predict their reactivities and behaviours in the two media. Hence, the frontier orbitals [28] were computed to calculate the gap values in the two media by using the same level of theory and later, with the gap values some global descriptors were calculated in order to predict the behaviours of those species of foscarnet in both media [2933]. In addition, the gap values together with the descriptors were compared with those reported in the literature for other antiviral agents, such as thymidine, cidofovir, brincidofovir, isothiazol derivatives, trifluridine, emtricitabine and idoxuridine [34-40].

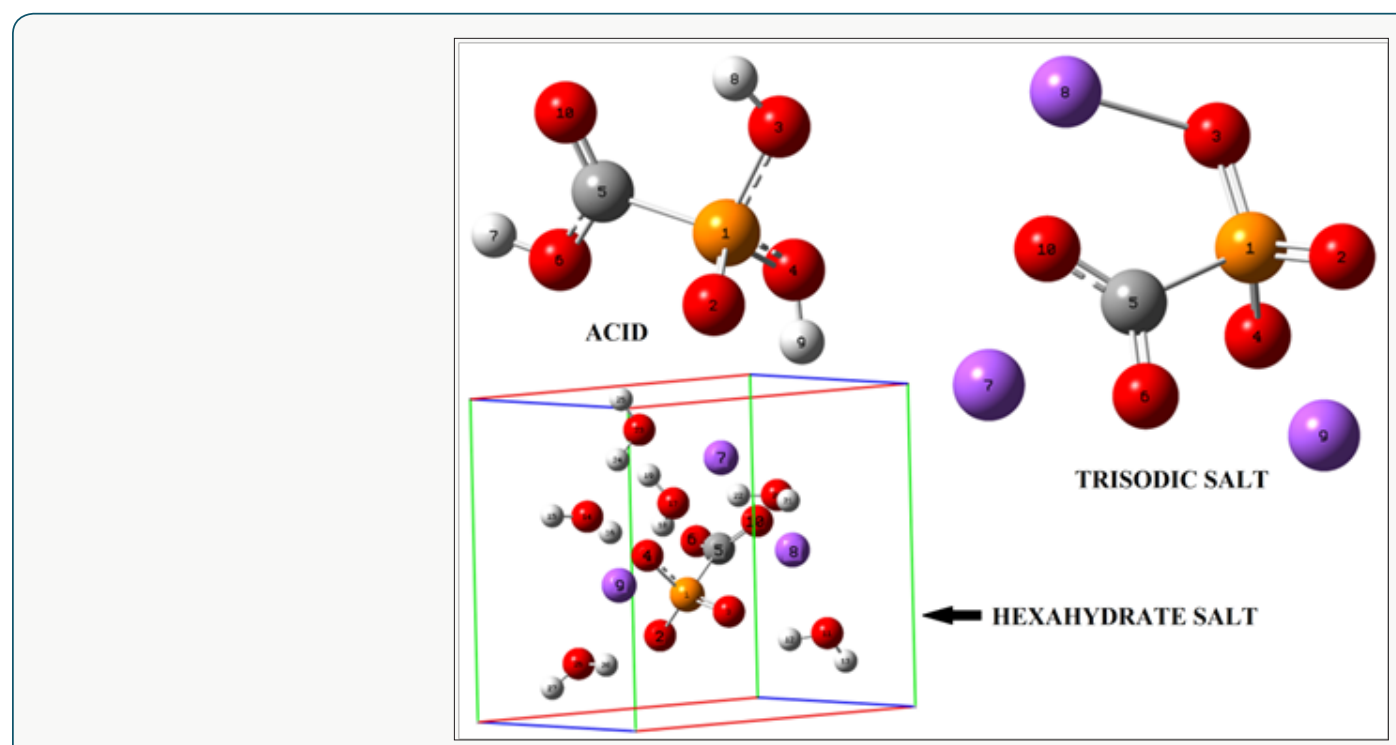

Figure 1: Molecular theoretical structures of the acid species and, anhydrous trisodic and hexa hydrated salts of foscarnet and the atoms numbering. 


\section{Methodology of calculations}

The structural modelled of the acid form and the trisodic salt of foscarnet were performed by using the GaussView program [41] while the hexa-hydrated trisodic species was built with the HyperChem program [42] adding water molecules to the periodic box size of the trisodic salt from one up to complete six, in similar form as were modelled the penta and dihydrate species of sucrose [43]. Here, an important factor is the orientation of water molecules around the $\mathrm{OH}$ groups of the trisodic salt because it determines their solvation energetics, as reported by Te et al. during a study on solvations of sugars [44]. Later, the optimizations of those species in gas phase were carried out with the Gaussian 09 package program [45] by using the hybrid B3LYP/6-311++G** method [21,22]. The three structures of those species of foscarnet can be seen in Figure 1 together with their corresponding labelling atoms. The self consistent reaction force field (SCRF) method with the polarized continuum (PCM) model were used $[23,24]$ in their optimizations in aqueous solution at the same level of theory because these models take in account the solvent effects while the solvation energies of those species were computed with the solvation model [25].

Their molecular electrostatic potential surfaces were calculated from the Merz-Singh-Kollman scheme [46] by using the Merz-Kollman (MK) charges and, in addition, the atomic natural population (NPA) together with the bond orders and stabilization energies were also considered. Hence, the NBO program was used to calculate those latter parameters from a natural bond orbital $[47,48]$ while the Bader`s theory and the AIM 2000 program were used to analyze and visualize the different interactions $[49,50]$. The frontiers orbitals [28] are interesting factors to predict reactivities and, also to compute global descriptors by using known equations [29-33]. The vibrational frequencies of all species were also calculated and later used to perform their complete assignments by using their force fields computed at the same level of theory and the experimental available infrared and Raman spectra for the hexa hydrated salt $[11,13]$. The vibrational assignments of acid and anhydrous salt were performed taking into account the potential energy distribution components (PED) $\geq 10 \%$ and their normal internal coordinates with the SQM procedure [26] and the Molvib program [27]. However, the complete assignments of the hexa hydrated salt were performed with the aid of the GaussView program [41]. Here, it is very important to mentioned that the hexa hydrated salt in gas phase was optimized but their frequencies were not obtained and only the IR spectrum could be predicted in solution by using the B3LYP/6-311++ $\mathrm{G}^{* *}$ method and, for this Table 1: Calculated total energy (E), dipolar moments $(\mu)$ and volume $(V)$ values for the three studied species of foscarnet in gas and aqueous solution phases.

\begin{tabular}{|c|c|c|c|c|c|c|}
\hline \multicolumn{9}{|c|}{ B3LYP/6-311++G**a } \\
\hline \multicolumn{9}{|c|}{ GAS PHASE } & \multicolumn{3}{c|}{ AQUEOUS SOLUTION/PCM } \\
\hline SPECIES & E (Hartrees) & $\mu$ (D) & V (Å3) & E (Hartrees) & $\mu$ (D) & V (Å3) \\
\hline ACID & -757.6230 & 2.73 & 100.6 & -757.6523 & 4.11 & 100.5 \\
\hline
\end{tabular}




\begin{tabular}{|c|c|c|c|c|c|c|}
\hline SALT & -1242.9240 & 14.03 & 222.7 & -1243.0206 & 12.65 & 232.1 \\
\hline $\mathrm{SALT} \bullet 6(\mathrm{H} 2 \mathrm{O})$ & -1701.8622 & 8.84 & 318.4 & -1701.9333 & 16.69 & 320.4 \\
\hline \multicolumn{7}{|c|}{ Solvation energy (kJ/mol) } \\
\hline SPECIES & $\Delta \mathrm{Gu} \#$ & $\Delta \mathrm{Gne}$ & $\Delta \mathrm{Gc}$ & $\Delta V(\AA \AA 3)$ & & \\
\hline ACID & -76.85 & 31.35 & -108.20 & -0.1 & & \\
\hline SALT & -253.38 & 14.55 & -267.93 & 9.4 & & \\
\hline $\mathrm{SALT} \bullet 6(\mathrm{H} 2 \mathrm{O})$ & -186.49 & 33.15 & -219.64 & 2.0 & & \\
\hline \multicolumn{7}{|c|}{ B3LYP/6-31G*a } \\
\hline $\mathrm{SALT} \bullet 6(\mathrm{H} 2 \mathrm{O})$ & -1701.4329 & 9.41 & 312.9 & -1701.5093 & 14.37 & 315.0 \\
\hline \multicolumn{7}{|c|}{ Solvation energy $(\mathrm{kJ} / \mathrm{mol})$} \\
\hline SPECIES & $\Delta \mathrm{G}_{\mathrm{u}} \#$ & $\Delta \mathrm{G}_{\mathrm{ne}}$ & $\Delta G_{c}$ & $\Delta V\left(\AA^{3}\right)$ & & \\
\hline $\mathrm{SALT} \bullet 6(\mathrm{H} 2 \mathrm{O})$ & -200.40 & 29.18 & -229.58 & 2.1 & & \\
\hline
\end{tabular}

aThis work, $\Delta \mathrm{G}_{\mathrm{u}} \#$, See text

Atomic Charges, Molecular Electrostatic Potential, Bond Orders

For the studied species of foscarnet is very interesting to investigate the distribution of the charges around the phosphate groups in order to know the influence of the water molecules on the atomic charges in the hexa hydrated salt in relation to the anhydrous salt and the acid species. Hence, two types of charges were studied, they are the atomic MK and NPA charges in gas and aqueous solution phases at the B3LYP/6-311++G** level of theory. The higher size basis set was used to calculate all properties for the hydrated salt because it produces the minima energies. Moreover, the molecular electrostatic potentials (MEP) and the bond orders (BO) were also predicted by using the same level of theory. The results of those two charges for the three species are presented in Table 2 together with their corresponding variations expressed as the differences between the values in solution and gas phase while

Table 2: Atomic MK and NPA charges for the three studied species of foscarnet in gas and aqueous solution phases and their corresponding variations $(\Delta)$ at B3LYP/6-311++G** level of theory.

\begin{tabular}{|c|c|c|c|c|c|c|c|c|c|c|}
\hline \multicolumn{11}{|c|}{ MK charges } \\
\hline \multicolumn{4}{|c|}{ ACID } & \multicolumn{4}{|c|}{ SALT } & \multicolumn{3}{|c|}{ SALT•6 (H20) } \\
\hline Atoms & GAS & PCM & $\Delta$ & Atoms & GAS & PCM & $\Delta$ & GAS & PCM & $\Delta$ \\
\hline $1 \mathrm{P}$ & 1.231 & 1.228 & -0.003 & $1 \mathrm{P}$ & 1.418 & 1.352 & -0.066 & 1.138 & 1.058 & -0.080 \\
\hline 20 & -0.783 & -0.791 & -0.008 & 20 & -0.940 & -0.968 & -0.028 & -0.917 & -0.828 & 0.089 \\
\hline 30 & -0.660 & -0.665 & -0.005 & 30 & -0.937 & -0.950 & -0.013 & -0.807 & -0.719 & 0.088 \\
\hline 40 & -0.706 & -0.678 & 0.028 & 40 & -0.939 & -0.969 & -0.030 & -0.821 & -0.732 & 0.089 \\
\hline $5 \mathrm{C}$ & 0.594 & 0.574 & -0.020 & $5 \mathrm{C}$ & 0.415 & 0.607 & 0.192 & 0.553 & 0.507 & -0.046 \\
\hline 60 & -0.667 & -0.653 & 0.014 & 60 & -0.776 & -0.766 & 0.010 & -0.758 & -0.711 & 0.047 \\
\hline $7 \mathrm{H}$ & 0.551 & 0.554 & 0.003 & $7 \mathrm{Na}$ & 0.881 & 0.865 & -0.016 & 0.931 & 0.877 & -0.054 \\
\hline $8 \mathrm{H}$ & 0.475 & 0.490 & 0.015 & $8 \mathrm{Na}$ & 0.867 & 0.875 & 0.008 & 0.927 & 0.859 & -0.068 \\
\hline $9 \mathrm{H}$ & 0.527 & 0.511 & -0.016 & $9 \mathrm{Na}$ & 0.854 & 0.872 & 0.018 & 0.906 & 0.837 & -0.069 \\
\hline 100 & -0.563 & -0.571 & -0.008 & 100 & -0.842 & -0.917 & -0.075 & -0.799 & -0.818 & -0.019 \\
\hline \multicolumn{11}{|c|}{ NPA charges } \\
\hline \multicolumn{4}{|c|}{ ACID } & \multicolumn{4}{|c|}{ SALT } & \multicolumn{3}{|c|}{ SALT•6 (H2O) } \\
\hline Atoms & GAS & PCM & $\Delta$ & Atoms & GAS & PCM & $\Delta$ & GAS & PCM & $\Delta$ \\
\hline
\end{tabular}




\begin{tabular}{|c|c|c|c|c|c|c|c|c|c|c|}
\hline $1 \mathrm{P}$ & 2.211 & 2.212 & 0.001 & $1 \mathrm{P}$ & 2.215 & 2.195 & -0.020 & 2.258 & 2.241 & -0.017 \\
\hline $2 \mathrm{O}$ & -1.096 & -1.104 & -0.008 & $2 \mathrm{O}$ & -1.193 & -1.229 & -0.036 & -1.233 & -1.212 & 0.021 \\
\hline $3 \mathrm{O}$ & -0.983 & -0.986 & -0.003 & $3 \mathrm{O}$ & -1.236 & -1.249 & -0.013 & -1.226 & -1.205 & 0.021 \\
\hline $4 \mathrm{O}$ & -0.979 & -0.984 & -0.005 & $4 \mathrm{O}$ & -1.193 & -1.229 & -0.036 & -1.197 & -1.217 & -0.020 \\
\hline $5 \mathrm{C}$ & 0.521 & 0.524 & 0.003 & $5 \mathrm{C}$ & 0.476 & 0.488 & 0.012 & 0.480 & 0.481 & 0.001 \\
\hline $6 \mathrm{O}$ & -0.673 & -0.673 & 0.000 & $6 \mathrm{O}$ & -0.867 & -0.784 & 0.083 & -0.825 & -0.834 & -0.009 \\
\hline $7 \mathrm{H}$ & 0.524 & 0.527 & 0.003 & $7 \mathrm{Na}$ & 0.876 & 0.864 & -0.012 & 0.906 & 0.886 & -0.020 \\
\hline $8 \mathrm{H}$ & 0.547 & 0.552 & 0.005 & $8 \mathrm{Na}$ & 0.936 & 0.937 & 0.001 & 0.860 & 0.860 & 0.000 \\
\hline $9 \mathrm{H}$ & 0.545 & 0.551 & 0.006 & $9 \mathrm{Na}$ & 0.910 & 0.929 & 0.019 & 0.868 & 0.866 & -0.002 \\
\hline $10 \mathrm{O}$ & -0.617 & -0.620 & -0.003 & $10 \mathrm{O}$ & -0.924 & -0.923 & 0.001 & -0.824 & -0.838 & -0.014 \\
\hline
\end{tabular}

Table 3: Molecular electrostatic potentials for the three studied species of foscarnet in gas and aqueous solution phases and their corresponding variations $(\Delta)$ at $\mathrm{B} 3 \mathrm{LYP} / 6-311++\mathrm{G}^{* *}$ level of theory.

\begin{tabular}{|c|c|c|c|c|c|c|c|c|c|c|}
\hline \multicolumn{4}{|c|}{ ACID } & \multicolumn{4}{c|}{ SALT } & \multicolumn{3}{c|}{ SALT•6 (H20) } \\
\hline Atoms & GAS & PCM & $\Delta$ & Atoms & GAS & PCM & $\Delta$ & GAS & PCM & $\Delta$ \\
\hline 1 P & -54.020 & -54.021 & -0.001 & $1 \mathrm{P}$ & -54.173 & -54.188 & -0.015 & -54.152 & -54.149 & 0.003 \\
\hline 2 O & -22.416 & -22.422 & -0.006 & 20 & -22.507 & -22.519 & -0.012 & -22.463 & -22.483 & -0.020 \\
\hline 3 O & -22.312 & -22.310 & 0.002 & 30 & -22.491 & -22.511 & -0.020 & -22.490 & -22.481 & 0.009 \\
\hline 4 O & -22.304 & -22.303 & 0.001 & $4 \mathrm{O}$ & -22.507 & -22.519 & -0.012 & -22.488 & -22.464 & 0.024 \\
\hline $5 \mathrm{C}$ & -14.591 & -14.592 & -0.001 & $5 \mathrm{C}$ & -14.707 & -14.726 & -0.019 & -14.698 & -14.699 & -0.001 \\
\hline $6 \mathrm{O}$ & -22.267 & -22.259 & 0.008 & $6 \mathrm{O}$ & -22.415 & -22.444 & -0.029 & -22.413 & -22.412 & 0.001 \\
\hline $7 \mathrm{H}$ & -0.880 & -0.874 & 0.006 & $7 \mathrm{Na}$ & -35.408 & -35.408 & 0.000 & -35.432 & -35.423 & 0.009 \\
\hline $8 \mathrm{H}$ & -0.901 & -0.896 & 0.005 & $8 \mathrm{Na}$ & -35.456 & -35.453 & 0.003 & -35.507 & -35.496 & 0.011 \\
\hline $9 \mathrm{H}$ & -0.895 & -0.887 & 0.008 & $9 \mathrm{Na}$ & -35.478 & -35.466 & 0.012 & -35.482 & -35.468 & 0.014 \\
\hline $10 \mathrm{O}$ & -22.339 & -22.349 & -0.010 & $10 \mathrm{O}$ & -22.408 & -22.425 & -0.017 & -22.414 & -22.411 & 0.003 \\
\hline
\end{tabular}

These results are in agreement with the higher volume variations observed for this species in solution and with their high solvation energy value. Here, the distribution of charges on the anhydrous species is totally modified in solution, as observed from their corresponding surface mapped presented in Figure 2 and, as evidenced by the different values observed in solution on all atoms from Table 3. The colorations observed from Figure 2 on all atoms in the acid species are very different from those observed on the anhydrous and hexa hydrated salts, thus, in the acid are observed red colours on the $\mathrm{O}$ atoms belong to the $\mathrm{PO} 3$ and $\mathrm{C}=0$ groups while on the $\mathrm{H}$ atoms belong to the $\mathrm{OH}$ groups are observed blue colours while in the two salts are observed only blue colours on the $\mathrm{Na}$ atoms because these regions are strongly electrophilic sites. Hence, strong nucleophilic and electrophilic sites are observed only for the acid species and, of course, different properties are expected for this species in relation to the two salts. Obviously, all green colorations observed on some regions in the three species are inert places where reactions with potential biological nucleophiles or electrophiles are not carried out.

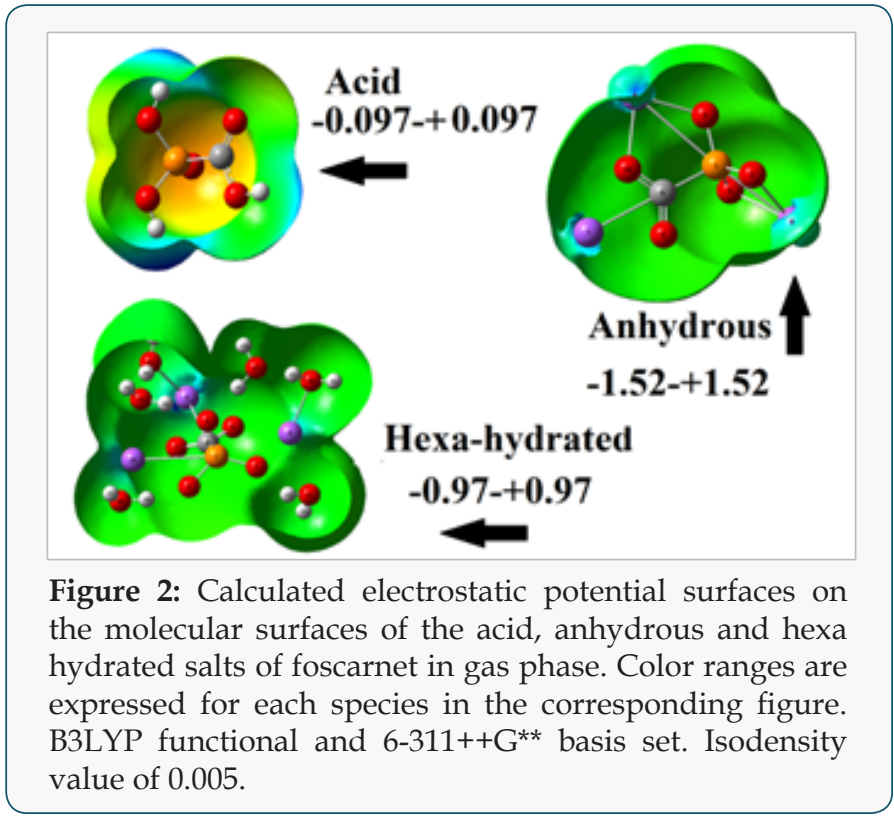

Table 4: Bond orders expressed as Wiberg indexes for the three studied species of foscarnet in gas and aqueous solution phases and their corresponding variations $(\Delta)$ at $\mathrm{B} 3 \mathrm{LYP} / 6-311++\mathrm{G}^{* *}$ level of theory.

\begin{tabular}{|c|c|c|c|c|c|c|c|c|c|c|}
\hline \multicolumn{4}{|c|}{ ACID } & \multicolumn{4}{c|}{ SALT } & \multicolumn{3}{c|}{ SALT•6 (H20) } \\
\hline Atoms & GAS & PCM & $\Delta$ & Atoms & GAS & PCM & $\Delta$ & GAS & PCM & $\Delta$ \\
\hline 1 P & 3.6933 & 3.687 & -0.006 & $1 \mathrm{P}$ & 3.794 & 3.777 & -0.017 & 3.704 & 3.733 & 0.029 \\
\hline
\end{tabular}




\begin{tabular}{|c|c|c|c|c|c|c|c|c|c|c|}
\hline 20 & 1.4872 & 1.473 & -0.014 & 20 & 1.342 & 1.281 & -0.061 & 1.298 & 1.322 & 0.024 \\
\hline 30 & 1.632 & 1.631 & -0.001 & 30 & 1.285 & 1.257 & -0.028 & 1.308 & 1.331 & 0.023 \\
\hline 40 & 1.6365 & 1.633 & -0.004 & 40 & 1.342 & 1.281 & -0.061 & 1.372 & 1.333 & -0.039 \\
\hline $5 \mathrm{C}$ & 3.7774 & 3.782 & 0.005 & $5 \mathrm{C}$ & 3.643 & 3.726 & 0.083 & 3.758 & 3.738 & -0.020 \\
\hline $6 \mathrm{O}$ & 2.0173 & 2.021 & 0.004 & $6 \mathrm{O}$ & 1.736 & 1.831 & 0.095 & 1.790 & 1.782 & -0.008 \\
\hline $7 \mathrm{H}$ & 0.7315 & 0.728 & -0.004 & $7 \mathrm{Na}$ & 0.239 & 0.259 & 0.020 & 0.190 & 0.226 & 0.036 \\
\hline $8 \mathrm{H}$ & 0.7047 & 0.699 & -0.006 & $8 \mathrm{Na}$ & 0.132 & 0.127 & -0.005 & 0.281 & 0.279 & -0.002 \\
\hline $9 \mathrm{H}$ & 0.7067 & 0.700 & -0.007 & $9 \mathrm{Na}$ & 0.181 & 0.141 & -0.040 & 0.265 & 0.267 & 0.002 \\
\hline $10 \mathrm{O}$ & 2.0252 & 2.021 & -0.004 & $10 \mathrm{O}$ & 1.654 & 1.656 & 0.002 & 1.789 & 1.774 & -0.015 \\
\hline
\end{tabular}

Table 5: Wiberg bond index matrix in the NAO basis for the anhydrous salt of foscarnet in gas and aqueous solution at the B3LYP/6$311++G^{* *}$ level of theory.

\begin{tabular}{|c|c|c|c|c|c|c|c|c|c|c|}
\hline \multicolumn{11}{|c|}{ Anhydrous salt/Gas phase } \\
\hline Atoms & 1 & 2 & 3 & 4 & 5 & 6 & 7 & 8 & 9 & 10 \\
\hline 1. $\mathrm{P}$ & 0 & 1.031 & 1.007 & 1.032 & 0.631 & 0.029 & 0.022 & 0.006 & 0.010 & 0.027 \\
\hline 2. 0 & 1.031 & 0.000 & 0.067 & 0.074 & 0.076 & 0.011 & 0.009 & 0.005 & 0.056 & 0.013 \\
\hline 3.0 & 1.007 & 0.067 & 0.000 & 0.067 & 0.057 & 0.009 & 0.008 & 0.061 & 0.006 & 0.003 \\
\hline 4.0 & 1.032 & 0.074 & 0.067 & 0.000 & 0.075 & 0.011 & 0.009 & 0.005 & 0.056 & 0.013 \\
\hline 5. C & 0.631 & 0.076 & 0.057 & 0.075 & 0.000 & 1.404 & 0.052 & 0.007 & 0.010 & 1.330 \\
\hline 6. 0 & 0.029 & 0.011 & 0.009 & 0.011 & 1.404 & 0.000 & 0.071 & 0.008 & 0.035 & 0.157 \\
\hline 7. $\mathrm{Na}$ & 0.022 & 0.009 & 0.008 & 0.009 & 0.052 & 0.071 & 0.000 & 0.001 & 0.001 & 0.065 \\
\hline 8. $\mathrm{Na}$ & 0.006 & 0.005 & 0.061 & 0.005 & 0.007 & 0.008 & 0.001 & 0.000 & 0.000 & 0.039 \\
\hline 9. $\mathrm{Na}$ & 0.010 & 0.056 & 0.006 & 0.056 & 0.010 & 0.035 & 0.001 & 0.000 & 0.000 & 0.006 \\
\hline 10. 0 & 0.027 & 0.013 & 0.003 & 0.013 & 1.330 & 0.157 & 0.065 & 0.039 & 0.006 & 0.000 \\
\hline \multicolumn{11}{|c|}{ Anhydrous salt/PCM } \\
\hline 1. $\mathrm{P}$ & 0 & 1.001 & 0.987 & 1 & 0.685 & 0.035 & 0.028 & 0.005 & 0.006 & 0.032 \\
\hline 2. 0 & 1.001 & 0.000 & 0.064 & 0.068 & 0.059 & 0.009 & 0.010 & 0.005 & 0.056 & 0.010 \\
\hline 3. 0 & 0.987 & 0.064 & 0.000 & 0.064 & 0.054 & 0.010 & 0.009 & 0.061 & 0.006 & 0.004 \\
\hline 4.0 & 1.000 & 0.068 & 0.064 & 0.000 & 0.059 & 0.009 & 0.010 & 0.005 & 0.056 & 0.010 \\
\hline 5. C & 0.685 & 0.059 & 0.054 & 0.059 & 0.000 & 1.489 & 0.045 & 0.005 & 0.010 & 1.320 \\
\hline 6. 0 & 0.035 & 0.009 & 0.010 & 0.009 & 1.489 & 0.000 & 0.090 & 0.009 & 0.004 & 0.175 \\
\hline 7. $\mathrm{Na}$ & 0.028 & 0.010 & 0.009 & 0.010 & 0.045 & 0.090 & 0.000 & 0.001 & 0.002 & 0.066 \\
\hline 8. $\mathrm{Na}$ & 0.005 & 0.005 & 0.061 & 0.005 & 0.005 & 0.009 & 0.001 & 0.000 & 0.000 & 0.036 \\
\hline 9. $\mathrm{Na}$ & 0.006 & 0.056 & 0.006 & 0.056 & 0.010 & 0.004 & 0.002 & 0.000 & 0.000 & 0.003 \\
\hline 10.0 & 0.032 & 0.010 & 0.004 & 0.010 & 1.320 & 0.175 & 0.066 & 0.036 & 0.003 & 0.000 \\
\hline
\end{tabular}

Another interesting property studied in the three species of foscarnet is the bond order (BO) expressed as Wiberg index. In Table 4 are summarized these results for the acid and the two salts in gas and aqueous solution phases at B3LYP/6-311++G** level of theory together with the variations observed when change the medium from the aqueous solution to the gas phase. Newly, the higher variations are observed in the anhydrous salt where in particular, the 02 and 04 atoms show decreasing in the $\mathrm{BO}$ as a consequence of their hydration while; in general, all the atoms of the acid species present low variations. The $\mathrm{Na} 7$ atom of the anhydrous salt in solution has the higher $\mathrm{BO}$ value while the $\mathrm{Na} 9$ atom presents the lower value in the same medium. On the contrary, in the Na8 and $\mathrm{Na} 9$ atoms of the hexa hydrated species in solution are observed the higher BO values different from the anhydrous ones. When the Wiberg bond index matrix in the NAO basis from Table 5 are analyzed by atoms for the anhydrous species, we observed:

I. That the Na7 atom are coordinated to the P1, C5, 06 and 010 atoms and,

II. That the BO of all these atoms increases from the gas phase to the solution with exception of the value corresponding to the $\mathrm{C} 5$ atom because their value decreases from 0.052 to 0.045 .

Analyzing the values for the Na8 atoms we observed practically the same coordination number in both media with the 03 and 010 atoms. In solution, the coordination three observed for the $\mathrm{Na} 9$ atom of this anhydrous salt in gas phase with the 02,04 and 
06 atoms decrease to two because in this medium practically disappear the coordination with the 06 atom. If now we analyze the BO matrix for the hexa hydrated species from Table 6 it is observed that the coordination number of the three $\mathrm{Na}$ atoms is different among them and different from the anhydrous species. Thus, the $\mathrm{Na} 7$ and Na9 atoms present coordination number four while the
$\mathrm{Na} 8$ atom coordination number two. The $\mathrm{BO}$ values for the Na7 and Na8 increase in solution justifying, this way, the lower volume variation observed for this species in this medium. Probably, these same reasons justify the lower Solvation energy observed for this hexa hydrated salt in relation to the anhydrous one.

Table 6: Wiberg bond index matrix in the NAO basis for the hexa hydrated salt of foscarnet in gas and aqueous solution at the B3LYP/6-311++G** level of theory.

\begin{tabular}{|c|c|c|c|c|c|c|c|c|c|c|}
\hline \multicolumn{11}{|c|}{ Gas phase } \\
\hline Atoms & 1 & 2 & 3 & 4 & 5 & 6 & 7 & 8 & 9 & 10 \\
\hline 1. $\mathrm{P}$ & 0.000 & 0.992 & 1.000 & 0.855 & 0.713 & 0.044 & 0.017 & 0.009 & 0.010 & 0.043 \\
\hline 2. 0 & 0.992 & 0.000 & 0.064 & 0.058 & 0.049 & 0.005 & 0.003 & 0.003 & 0.047 & 0.011 \\
\hline 3. 0 & 1.000 & 0.064 & 0.000 & 0.052 & 0.050 & 0.011 & 0.003 & 0.051 & 0.002 & 0.004 \\
\hline 4. 0 & 0.855 & 0.058 & 0.052 & 0.000 & 0.058 & 0.013 & 0.003 & 0.005 & 0.011 & 0.013 \\
\hline 5. C & 0.713 & 0.049 & 0.050 & 0.058 & 0.000 & 1.420 & 0.024 & 0.010 & 0.011 & 1.418 \\
\hline 6.0 & 0.044 & 0.005 & 0.011 & 0.013 & 1.420 & 0.000 & 0.043 & 0.008 & 0.055 & 0.186 \\
\hline 7. $\mathrm{Na}$ & 0.017 & 0.003 & 0.003 & 0.003 & 0.024 & 0.043 & 0.000 & 0.001 & 0.002 & 0.045 \\
\hline 8. $\mathrm{Na}$ & 0.009 & 0.003 & 0.051 & 0.005 & 0.010 & 0.008 & 0.001 & 0.000 & 0.000 & 0.058 \\
\hline 9. $\mathrm{Na}$ & 0.010 & 0.047 & 0.002 & 0.011 & 0.011 & 0.055 & 0.002 & 0.000 & 0.000 & 0.007 \\
\hline 10. 0 & 0.043 & 0.107 & 0.004 & 0.013 & 1.418 & 0.186 & 0.045 & 0.058 & 0.007 & 0.000 \\
\hline \multicolumn{11}{|c|}{ PCM } \\
\hline 1. $\mathrm{P}$ & 0.000 & 1.008 & 1.007 & 0.889 & 0.698 & 0.038 & 0.021 & 0.009 & 0.009 & 0.038 \\
\hline 2.0 & 1.008 & 0.000 & 0.063 & 0.600 & 0.053 & 0.005 & 0.004 & 0.004 & 0.054 & 0.011 \\
\hline 3. 0 & 1.007 & 0.063 & 0.000 & 0.056 & 0.056 & 0.012 & 0.004 & 0.058 & 0.004 & 0.006 \\
\hline 4.0 & 0.889 & 0.600 & 0.056 & 0.000 & 0.063 & 0.013 & 0.005 & 0.005 & 0.013 & 0.012 \\
\hline 5. C & 0.698 & 0.053 & 0.056 & 0.063 & 0.000 & 1.411 & 0.031 & 0.009 & 0.010 & 1.404 \\
\hline 6.0 & 0.038 & 0.005 & 0.012 & 0.013 & 1.411 & 0.000 & 0.055 & 0.007 & 0.054 & 0.179 \\
\hline 7. $\mathrm{Na}$ & 0.021 & 0.004 & 0.004 & 0.005 & 0.031 & 0.055 & 0.000 & 0.001 & 0.002 & 0.059 \\
\hline 8. Na & 0.009 & 0.004 & 0.058 & 0.005 & 0.009 & 0.007 & 0.001 & 0.000 & 0.000 & 0.055 \\
\hline 9. $\mathrm{Na}$ & 0.009 & 0.054 & 0.004 & 0.013 & 0.010 & 0.054 & 0.002 & 0.000 & 0.000 & 0.007 \\
\hline 10.0 & 0.038 & 0.011 & 0.006 & 0.012 & 1.404 & 0.179 & 0.059 & 0.055 & 0.007 & 0.000 \\
\hline
\end{tabular}

\section{Stabilities of the Species in Both Media}

The stabilities of the three species of foscarnet were studied by using the donor-acceptor energy interactions and the topological properties because different types of interactions are expected due to the presences of $\mathrm{Na}$ atoms in the two salts. Hence, the donoracceptor energy interactions for the three species of foscarnet obtained from the NBO $[47,48]$ calculations can be seen in Table 7. Regarding the results from Table 7 , four different interactions can be observed in these species which are the $\mathrm{LP} \rightarrow \sigma^{*}, \mathrm{LP} \rightarrow \pi^{*}$, $\sigma^{*} \rightarrow \sigma^{*}$ and $\mathrm{LP}^{*} \rightarrow \mathrm{LP}^{*}$ interactions whose first three energies are named E1, E2 and E3, respectively. The first two interactions are de localizations observed from the lone pairs (LP) of $\mathrm{O}$ atoms toward $\sigma^{*} \mathrm{P}-\mathrm{O}, \mathrm{P}-\mathrm{C}, \mathrm{C}-\mathrm{O}$ or $\mathrm{O}-\mathrm{H}$ orbital's while the $\mathrm{LP} \rightarrow \sigma^{*} \mathrm{O}-\mathrm{H}$ interactions are only observed in the hexa hydrated salt due to the water molecules. Hence, the acid species present the lower number of interactions in both media and, for these reasons, low total energy values are observed in those media and, as a consequence this species in solution is the less stable than the other ones while the anhydrous salt in the gas phase is the most stable (1464.17 kJ/ mol) due to the $\sigma^{*} \rightarrow \sigma^{*}$ and $\mathrm{LP}^{*} \rightarrow \mathrm{LP}^{*}$ interactions only observed for this salt in this media. On the contrary, the hexa hydrated salt is the most stable in solution due to the $\mathrm{LP} \rightarrow \sigma^{*} \mathrm{O}-\mathrm{H}$ interactions. Different interactions can be easily investigated by using the Bader's theory of atoms in molecules (AIM) [49] by means of the topological properties calculated in the Bond Critical Points (BCPs) with the AIM2000 program [50]. Thus, when the electron density, $\rho(r)$, the Laplacian, $\tilde{N} 2 \rho(r)$, the eigenvalues $(\lambda 1, \lambda 2, \lambda 3)$ of the Hessian matrix and, the $|\lambda 1| / \lambda 3$ ratio are calculated and, in particular, when the $|\lambda 1| / \lambda 3<1$ and $\tilde{N} 2 \rho(r)>0$ it is possible to predict $\mathrm{H}$ bonds or ionic interactions. In this work, only for the two salts are observed intra-molecular and the $\mathrm{H}$ bonds interactions in both media and, their topological properties obtained by using the B3LYP/6-311++G** method are presented in Tables 8 \& 9. 
Table 7: Main donor-acceptor energy interactions (in $\mathrm{kJ} / \mathrm{mol}$ ) for the three studied species of foscarnet in gas and aqueous solution phases and their corresponding variations $(\Delta)$ at B3LYP/6-311++G** level of theory.

\begin{tabular}{|c|c|c|c|c|c|}
\hline \multirow{2}{*}{ Delocalization's } & \multicolumn{2}{|c|}{ ACID } & \multicolumn{2}{|c|}{ SALT } & \multirow{2}{*}{$\begin{array}{c}\text { SALT•6 (H20) } \\
\text { PCM }\end{array}$} \\
\hline & GAS & PCM & GAS & PCM & \\
\hline $\mathrm{LP}(2) \mathrm{O} 2 \rightarrow \sigma^{*} \mathrm{P} 1-03$ & & & 65.92 & 58.98 & \\
\hline $\mathrm{LP}(3) 02 \rightarrow \sigma * \mathrm{P} 1-03$ & 75.91 & & & & 55.18 \\
\hline $\mathrm{LP}(2) 02 \rightarrow \sigma * \mathrm{P} 1-04$ & & & 50.33 & 42.68 & 47.86 \\
\hline $\mathrm{LP}(3) \mathrm{O} 2 \rightarrow \sigma^{*} \mathrm{P} 1-\mathrm{C} 4$ & & 75.45 & & & \\
\hline $\mathrm{LP}(3) \mathrm{O} 2 \rightarrow \sigma * \mathrm{P} 1-\mathrm{C} 5$ & & & & 65.96 & \\
\hline $\mathrm{LP}(2) \mathrm{O} 2 \rightarrow \sigma * \mathrm{P} 1-\mathrm{C} 5$ & 80.47 & 74.95 & 71.60 & 63.45 & 64.96 \\
\hline $\mathrm{LP}(3) 03 \rightarrow \sigma * \mathrm{P} 1-02$ & & & & 50.79 & \\
\hline $\mathrm{LP}(2) \mathrm{O} 3 \rightarrow \sigma^{*} \mathrm{P} 1-02$ & 45.35 & & 53.09 & & 65.08 \\
\hline $\mathrm{LP}(3) \mathrm{O} 3 \rightarrow \sigma^{*} \mathrm{P} 1-04$ & & & 0.00 & 50.12 & 64.41 \\
\hline $\mathrm{LP}(2) 03 \rightarrow \sigma * \mathrm{P} 1-04$ & & & 53.30 & & \\
\hline $\mathrm{LP}(3) \mathrm{O} 3 \rightarrow \sigma * \mathrm{P} 1-\mathrm{C} 5$ & & & 73.36 & & \\
\hline $\mathrm{LP}(2) 04 \rightarrow \sigma * \mathrm{P} 1-02$ & & & 50.54 & 42.68 & 52.71 \\
\hline $\mathrm{LP}(2) 04 \rightarrow \sigma^{*} \mathrm{P} 1-03$ & & & 65.79 & 58.94 & \\
\hline $\mathrm{LP}(3) 04 \rightarrow \sigma^{*}$ 014-H16 & & & & & 78.54 \\
\hline $\mathrm{LP}(2) 04 \rightarrow \sigma^{*} \mathrm{0} 17-\mathrm{H} 18$ & & & & & 40.92 \\
\hline $\mathrm{LP}(3) 04 \rightarrow \sigma * \mathrm{P} 1-03$ & & & & & 58.52 \\
\hline $\mathrm{LP}(3) 04 \rightarrow \sigma * \mathrm{P} 1-\mathrm{C} 5$ & & & 71.85 & 65.88 & \\
\hline $\mathrm{LP}(3) 04 \rightarrow \sigma * 014-\mathrm{H} 16$ & & & & & 78.54 \\
\hline $\mathrm{LP}(2) 06 \rightarrow \sigma * \mathrm{P} 1-\mathrm{C} 5$ & & & 47.36 & 62.49 & 56.68 \\
\hline $\mathrm{LP}(2) 06 \rightarrow \sigma * \mathrm{C} 5-010$ & & & 69.81 & 67.88 & 69.18 \\
\hline $\mathrm{LP}(2) 010 \rightarrow \sigma^{*} \mathrm{P} 1-\mathrm{C} 5$ & 92.46 & 91.88 & 47.11 & 53.84 & 56.39 \\
\hline $\mathrm{LP}(2) 010 \rightarrow \sigma^{*} \mathrm{C} 5-06$ & 121.81 & 119.05 & 58.77 & 56.51 & 67.21 \\
\hline $\mathrm{LP}(2) 014 \rightarrow \sigma * 023-\mathrm{H} 24$ & & & & & 50.29 \\
\hline $\mathrm{LP}(2) 017 \rightarrow \sigma * 020-\mathrm{H} 22$ & & & & & 75.66 \\
\hline $\mathrm{E} 1=\mathrm{LP} \rightarrow \sigma^{*}$ & 211.88 & 361.32 & 778.82 & 740.19 & 982.13 \\
\hline $\mathrm{LP}(2) 06 \rightarrow \pi * \mathrm{C} 5-010$ & 211.88 & 218.74 & & & \\
\hline $\mathrm{LP}(3) 010 \rightarrow \pi * \mathrm{C} 5-06$ & & & 335.36 & 339.21 & 398.52 \\
\hline $\mathrm{E} 2=\mathrm{LP} \rightarrow \pi^{*}$ & 211.88 & 218.74 & 335.36 & 339.21 & 398.52 \\
\hline$\sigma * \mathrm{P} 1-03 \rightarrow \sigma * \mathrm{P} 1-02$ & & & 132.42 & & \\
\hline$\sigma * \mathrm{P} 1-03 \rightarrow \sigma * \mathrm{P} 1-04$ & & & 130.83 & & \\
\hline $\mathrm{E} 3=\sigma^{*} \rightarrow \sigma^{*}$ & & & 263.26 & & \\
\hline $\mathrm{LP}^{*}(1) \mathrm{Na} 7 \rightarrow \mathrm{LP}^{*}(2) \mathrm{Na} 7$ & & & 86.74 & & \\
\hline$\Delta \mathrm{ETn} \rightarrow \pi^{*}$ & 423.77 & 580.06 & 1464.17 & 1079.40 & 1380.65 \\
\hline
\end{tabular}

Table 8: Analysis of the topological properties for the anhydrous salt of foscarnet in gas and aqueous solution phases at B3LYP/6$311++G^{* *}$ level of theory.

\begin{tabular}{|c|c|c|c|c|c|c|c|c|c|c|c|}
\hline \multicolumn{12}{|c|}{ GAS PHASE SAIT FORM } \\
\hline Parameter & O6-Na 7 & O10-Na7 & RCP1 & O3-Nas & O10-Nas & RCP2 & Oz-Nas & O6-Na9 & RCP3 & O4-Na9 & RCP4 \\
\hline $\begin{array}{l}p^{\prime}(r) \\
v^{2} p(r)\end{array}$ & $\begin{array}{l}0.0303 \\
0.1962\end{array}$ & $\begin{array}{l}0.0286 \\
0.1823\end{array}$ & $\begin{array}{l}0.0205 \\
0.1270\end{array}$ & $\begin{array}{l}0.0379 \\
0.2726\end{array}$ & $\begin{array}{l}0.0263 \\
0.1675\end{array}$ & $\begin{array}{l}0.0110 \\
0.0482\end{array}$ & $\begin{array}{l}0.0259 \\
0.1539\end{array}$ & $\begin{array}{l}0.0159 \\
0.0870\end{array}$ & $\begin{array}{l}0.0108 \\
0.0551\end{array}$ & $\begin{array}{l}0.0260 \\
0.1544\end{array}$ & $\begin{array}{l}0.0210 \\
0.1104\end{array}$ \\
\hline $\begin{array}{c}V_{p} p\left(r_{c}\right) \\
\lambda_{-2}\end{array}$ & -0.0386 & -0.0358 & -0.0202 & $\begin{array}{r}0.0531 \\
-0.0531\end{array}$ & $\begin{array}{r}0.1675 \\
-0.0345\end{array}$ & $\begin{array}{c}0.0482 \\
-0.0080\end{array}$ & $\begin{array}{c}0.1539 \\
-0.0301\end{array}$ & $\begin{array}{r}0.0870 \\
-0.0175\end{array}$ & $\begin{array}{r}0.0551 \\
-0.0033\end{array}$ & $\begin{array}{c}0.1544 \\
-0.0302\end{array}$ & $\begin{array}{r}0.1104 \\
-0.0191\end{array}$ \\
\hline$\lambda_{2}$ & -0.0385 & -0.0349 & 0.0398 & -0.0504 & -0.0332 & 0.0226 & -0.0239 & -0.0174 & 0.0209 & -0.0240 & 0.0152 \\
\hline$\lambda_{3}$ & 0.2734 & 0.2531 & 0.1074 & 0.3762 & 0.2357 & 0.0335 & 0.2079 & 0.1220 & 0.0375 & 0.2086 & 0.1142 \\
\hline$\left|\lambda_{a}\right| \lambda_{3}$ & 0.1412 & 0.1414 & 0.1881 & 0.1411 & 0.1476 & 0.2388 & 0.1448 & 0.1434 & 0.0850 & $0.144 \mathrm{~S}$ & 0.1673 \\
\hline $\begin{array}{l}\text { Distance } \\
\text { (A) }\end{array}$ & 2.191 & 2.216 & & 2.089 & 2.244 & & 2.279 & 2.455 & & 2.278 & \\
\hline \multicolumn{12}{|c|}{ AQUEOUS SOLUTION SAIT FORM } \\
\hline $\begin{array}{c}\text { Parameter } \\
(a, u,)\end{array}$ & O6-Na7 7 & O10-Na7 & RCP1 & O3-Nas & O10-Nas & $\mathrm{RCP} 2$ & O2-Nas & O6-Na9 & RCP3 & O4-Na9 & RCP4 \\
\hline$p(r d)$ & 0.0236 & 0.0229 & 0.0172 & 0.0292 & 0.0251 & 0.0117 & 0.0243 & & & 0.0244 & 0.0173 \\
\hline$\nabla^{2} \rho\left(r_{c}\right)$ & 0.1311 & 0.130 .4 & 0.0945 & 0.1893 & 0.1596 & 0.0459 & 0.1419 & & & 0.1424 & 0.0889 \\
\hline$\lambda_{2}$ & -0.0271 & -0.0264 & -0.0160 & -0.0375 & -0.0328 & -0.0084 & -0.0273 & & & -0.0274 & -0.0146 \\
\hline$\lambda=$ & -0.0264 & -0.0252 & 0.0278 & -0.0354 & -0.0314 & 0.0175 & -0.0267 & & & -0.0268 & 0.0249 \\
\hline$\lambda_{3}$ & 0.1847 & 0.1821 & 0.0827 & 0.2623 & 0.2239 & 0.0368 & 0.1960 & & & 0.1966 & 0.0786 \\
\hline$\left|\lambda_{2}\right| / \lambda_{-}=$ & 0.1467 & 0.1450 & 0.1935 & 0.1430 & 0.1465 & 0.2283 & 0.1393 & & & 0.1394 & 0.1858 \\
\hline $\begin{array}{l}\text { Distance } \\
\text { (A) }\end{array}$ & 2.313 & 2.320 & & 2.203 & 2.259 & & 2.297 & 4.004 & & 2.296 & \\
\hline
\end{tabular}

Citation: Maximiliano A I, Silvia A B. Structural and Vibrational Study On the Acid, Hexa-Hydrated and Anhydrous Trisodic Salts of 
Table 9: Analysis of the topological properties for the hexa hydrated salt of foscarnet in gas and aqueous solution phases at B3LYP/6$311++G^{* *}$ level of theory.

\begin{tabular}{|c|c|c|c|c|c|c|c|c|}
\hline \multicolumn{9}{|c|}{ GAS PHASE SALT $\bullet\left(\mathrm{H}_{2} \mathrm{O}\right) / \mathrm{B} 3 \mathrm{~L}$ YP $6-311+\mathrm{G}^{* *}$} \\
\hline $\begin{array}{c}\text { Parameter } \\
(a, u,)\end{array}$ & O2--H16w & O2--H18w & O3-- $\mathrm{Hl2w}$ & O3-- Na5 & O4--H28w & $\mathrm{O} 4-\mathrm{Na} 10$ & $\mathrm{Na5}-\mathrm{O}$ - & $\mathrm{Na5}-\mathrm{O} 11 \mathrm{w}$ \\
\hline$\rho\left(r_{\mathrm{e}}\right)$ & 0.0839 & 0.0494 & 0.0402 & 0.0229 & 0.0410 & 0.0218 & 0.0213 & 0.0183 \\
\hline$\nabla^{2} \rho\left(r_{\mathrm{s}}\right)$ & 0.1665 & 0.1484 & 0.1448 & 0.1442 & 0.1498 & 0.1312 & 0.1288 & 0.1198 \\
\hline$\lambda_{2}$ & -0.1846 & -0.0868 & -0.0617 & -0.0285 & -0.0631 & -0.0258 & -0.0271 & -0.0220 \\
\hline$\lambda_{2}$ & -0.1804 & -0.0822 & -0.0587 & -0.0275 & -0.0610 & -0.0253 & -0.0261 & -0.0207 \\
\hline$\lambda_{s}$ & 0.5316 & 0.3175 & 0.2652 & 0.2002 & 0.2740 & 0.1824 & 0.1821 & 0.1625 \\
\hline$\lambda_{a} / / \lambda_{a s}$ & 0.3473 & 0.2734 & 0.2327 & 0.1424 & 0.2303 & 0.1414 & 0.1488 & 0.1354 \\
\hline $\begin{array}{c}\text { Distance } \\
(\mathrm{A})\end{array}$ & 1.453 & 1.653 & 1.731 & 2.291 & 1.714 & 2.324 & 2.326 & 2.333 \\
\hline $\begin{array}{c}\text { Parameter } \\
(\mathrm{a}, \mathrm{u},)\end{array}$ & $\mathrm{NaS}-\mathrm{O} 20 \mathrm{w}$ & $\mathrm{Na9--O7}$ & $\mathrm{Na9}-\mathrm{O}$ & $\mathrm{Na9}--\mathrm{O} 23 \mathrm{w}$ & Nal0--O7 & $\begin{array}{c}\text { Nal0-- } \\
\text { O14w }\end{array}$ & $\begin{array}{c}\text { Nal0-- } \\
\text { O26w }\end{array}$ & \\
\hline$\rho\left(r_{e}\right)$ & 0.0225 & 0.0246 & 0.0223 & 0.0233 & 0.0227 & 0.0168 & 0.0197 & \\
\hline$\nabla^{2} \rho\left(r_{e}\right)$ & 0.1420 & 0.1588 & 0.1395 & 0.1559 & 0.1396 & 0.0961 & 0.1334 & \\
\hline$\lambda_{2}$ & -0.0297 & -0.0305 & -0.0267 & -0.0317 & -0.0292 & -0.0200 & -0.0238 & \\
\hline$\lambda a$ & -0.0280 & -0.0288 & -0.0240 & -0.0289 & -0.0281 & -0.0193 & -0.0230 & \\
\hline$\lambda_{s}$ & 0.1997 & 0.2181 & 0.1902 & 0.2165 & 0.1969 & 0.1355 & 0.1803 & \\
\hline$p_{a} / / \lambda_{a s}$ & 0.1487 & 0.1398 & 0.1404 & 0.1464 & 0.1483 & 0.1476 & 0.1320 & \\
\hline $\begin{array}{c}\text { Distance } \\
(\mathcal{A})\end{array}$ & 2.292 & 2.258 & 2.301 & 2.258 & 2.300 & 2.419 & 2.295 & \\
\hline \multicolumn{9}{|c|}{ AQUEOUS SOLUTION SALT $\bullet 6\left(\mathrm{H}_{2} \mathrm{O}\right) / \mathrm{B} 3 \mathrm{LYP} / 6-311+\mathrm{G}^{*} *$} \\
\hline $\begin{array}{c}\text { Parameter } \\
(\mathrm{a}, \mathrm{u},)\end{array}$ & O2--H16w & O2--H18w & $\mathrm{O}--\mathrm{H} 12 \mathrm{w}$ & O3--Na5 & O4--H28w & O4--Na10 & $\mathrm{Na5}-\mathrm{OS}$ & $\mathrm{Na5}-\mathrm{O} 11 \mathrm{w}$ \\
\hline$\rho\left(r_{s}\right)$ & 0.0437 & 0.0439 & 0.0323 & 0.0194 & 0.0317 & 0.0155 & 0.0217 & 0.0178 \\
\hline$\nabla^{2} \rho\left(r_{e}\right)$ & 0.1176 & 0.1324 & 0.1117 & 0.1100 & 0.1121 & 0.0787 & 0.1329 & 0.1060 \\
\hline$\lambda_{2}$ & -0.0699 & -0.0727 & -0.0454 & -0.0223 & -0.0443 & -0.0161 & -0.0277 & -0.0216 \\
\hline$\lambda_{z}$ & -0.0675 & -0.0698 & -0.0421 & -0.0214 & -0.0413 & -0.0152 & -0.0267 & -0.0196 \\
\hline$\lambda s$ & 0.2551 & 0.2750 & 0.1992 & 0.1537 & 0.1978 & 0.1101 & 0.1873 & 0.1471 \\
\hline$D_{-a} / / \lambda_{a}$ & 0.2740 & 0.2644 & 0.2279 & 0.1451 & 0.2240 & 0.1462 & 0.1479 & 0.1468 \\
\hline $\begin{array}{c}\text { Distance } \\
(\AA)\end{array}$ & 1.728 & 1.702 & 1.838 & 2.381 & 1.834 & 2.500 & 2.314 & 2.383 \\
\hline $\begin{array}{c}\text { Parameter } \\
(a, u,)\end{array}$ & $\mathrm{Nas}-\mathrm{O} 20 \mathrm{w}$ & $\mathrm{Na9--O} 7$ & $\mathrm{Na9--OS}$ & $\mathrm{Na9}-\mathrm{O} 23 \mathrm{w}$ & Nal0--O7 & $\begin{array}{l}\text { Nal0-- } \\
\text { O14w }\end{array}$ & $\begin{array}{l}\text { Nal0-- } \\
\text { O26w }\end{array}$ & \\
\hline$\rho\left(r_{\mathrm{s}}\right)$ & 0.0224 & 0.0205 & 0.0196 & 0.0230 & 0.0217 & 0.0184 & 0.0195 & \\
\hline$\nabla^{2} p\left(r_{s}\right)$ & 0.1420 & 0.1170 & 0.1102 & 0.1498 & 0.1306 & 0.1119 & 0.1171 & \\
\hline$\lambda_{2}$ & -0.0298 & -0.0233 & -0.0220 & -0.0310 & -0.0274 & -0.0231 & -0.0240 & \\
\hline$\lambda_{2}$ & -0.0281 & -0.0222 & -0.0204 & -0.0288 & -0.0264 & -0.0221 & -0.0224 & \\
\hline$\lambda_{a}$ & 0.2000 & 0.1626 & 0.1526 & 0.2096 & 0.1845 & 0.1572 & 0.1636 & \\
\hline$D_{a} / / 7$. & 0.1490 & 0.1433 & 0.1442 & 0.1479 & 0.1485 & 0.1469 & 0.1467 & \\
\hline $\begin{array}{c}\text { Distance } \\
(\mathbb{A})\end{array}$ & 2.293 & 2.354 & 2.375 & 2.275 & 2.319 & 2.367 & 2.350 & \\
\hline
\end{tabular}

The topological properties calculated in the Ring Critical Point (RCPs) are also presented in both tables. In the anhydrous species in gas phase are observed seven different intra-molecular $\mathrm{O}---\mathrm{Na}$ interactions generating four RCPs while in solution only six $\mathrm{O}---\mathrm{Na}$ interactions are observed and three RCPs. Note that the 06---Na9 interaction disappear in solution together with the corresponding RCP3. Obviously, the large distance of $4.004 \AA$ observed between those two 06 and $\mathrm{Na} 9$ atoms involved justify such observation. For this same reason in gas phase, the 03---Na8 interaction show the higher values in the topological properties because the distance between the two atoms is the lowest (2.089 $\AA$ ) than the other ones. When the topological properties are analyzed for the hydrated salt we observed the same numbers of interactions in both media, thus, eleven inter- molecular $\mathrm{O}---\mathrm{Na}$ and four $\mathrm{H}$ bonds $\mathrm{O}---\mathrm{H}$ interactions are observed. Here, with the w letter are identified those interactions related with the $\mathrm{O}$ and $\mathrm{H}$ atoms corresponding to the water molecules of this hydrated salt. A very important observation is the low values in the distances $\mathrm{O}---\mathrm{H}$ in gas phase in relation to the values in solution. As a result, the presences of water molecules of the solvent justify the higher distances in solution. For this salt, we also observed that those interactions where the distances between the atoms involved are lower than the other ones their topological properties present higher values. Hence, in both media the four $\mathrm{O}---\mathrm{H}$ interactions and the intra-molecular Na9---07 and Na9---023 interactions have the higher values. This AIM study clearly evidences the high stability of the hexa hydrated salt in both media while the NBO study reveals a higher stability for the anhydrous salt.

\section{HOMO-LUMO Study and Global Descriptors}

The gap parameters, expressed as the difference between both frontier orbital's, are very useful to predict the reactivities of different species because when their value is high a low reactivity is expected for this species. Besides, with the gap value it is possible to calculate a series of global descriptors used to predict their behaviour in different media. Thus, for the three studied species 
of foscarnet in gas and aqueous solution the frontier orbital's and chemical potential $(\mu)$, electro negativity $(\chi)$, global hardness $(\eta)$, global softness $(S)$, global electrophilicity index $(\omega)$ and global nucleophilicity index (E) were calculated at B3LYP/6-311++G** level of theory. The values are presented in Table 10 together with their corresponding equations. Analyzing first the gap values it is observed that the anhydrous salt is the most reactive species in both media and, in particular in solution, as expected because this species has higher solvation energy and volume variation, as observed from Table 1. On the other hand, the hydrated salt is most reactive than the acid species probably due to that this acid species practically do not modify their volume in solution. In reference to the descriptors, the global hardness and softness values are in agreement with the most reactive species, thus, the higher hardness values are observed for the anhydrous and hydrated salt while the higher softness values are observed in both media for the most reactive anhydrous species. The anhydrous salt evidence the higher electrophilicity index and the lower values are observed for the hexa hydrated salt in both media. The above parameters were compared with values reported for other antiviral agents, such as thymidine, cidofovir, brincidofovir, isothiazol derivatives, trifluridine, emtricitabine and idoxuridine [34-40]. These comparisons are summarized in Table 11 and they correspond to the conformations most stable in solution and, only for cidofovir and brincidofovir the values presented were those obtained in gas phase.

Table 10: Calculated HOMO and LUMO orbitals and chemical potential $(\mu)$, electro negativity $(\chi)$, global hardness ( $\eta)$, global softness (S), global electrophilicity index $(\omega)$ and global nucleophilicity index $(\mathrm{E})$ (in $\mathrm{eV}$ ) for the three studied species of foscarnet in gas and aqueous solution.

\begin{tabular}{|c|c|c|c|c|c|c|}
\hline \multicolumn{7}{|c|}{ B3LYP/6-311++G**a } \\
\hline \multirow{2}{*}{ Orbitals } & \multicolumn{2}{|c|}{ ACID } & \multicolumn{2}{|c|}{ SALT } & \multicolumn{2}{|c|}{ SALT•6 (H2O) } \\
\hline & GAS & PCM & GAS & PCM & GAS & PCM \\
\hline HOMO & -8.3252 & -8.2658 & -4.8511 & -4.3762 & -6.9135 & -5.5549 \\
\hline LUMO & -1.4152 & -1.3618 & -1.9335 & -1.8447 & -0.6413 & -1.5869 \\
\hline$|\mathrm{GAP}|$ & 6.9100 & 6.9040 & 2.9176 & 2.5315 & 6.2722 & 3.9680 \\
\hline \multicolumn{7}{|c|}{ DESCRIPTORS } \\
\hline \multirow{2}{*}{$(\mathrm{eV})$} & \multicolumn{2}{|c|}{ ACID } & \multicolumn{2}{|c|}{ SALT } & \multicolumn{2}{|c|}{ SALT•6 (H20) } \\
\hline & GAS & PCM & GAS & PCM & GAS & PCM \\
\hline$\chi$ & -3.4550 & -3.4520 & -1.4588 & -1.2658 & -3.1361 & -1.9840 \\
\hline$\mu$ & -4.8702 & -4.8138 & -3.3923 & -3.1105 & -3.7774 & -3.5709 \\
\hline$\eta$ & 3.4550 & 3.4520 & 1.4588 & 1.2658 & 3.1361 & 1.9840 \\
\hline S & 0.1447 & 0.1448 & 0.3427 & 0.3950 & 0.1594 & 0.2520 \\
\hline$\omega$ & 3.4325 & 3.3564 & 3.9442 & 3.8218 & 2.2749 & 3.2135 \\
\hline $\mathrm{E}$ & -16.8265 & -16.6172 & -4.9487 & -3.9371 & -11.8463 & -7.0847 \\
\hline
\end{tabular}

Table 11: Calculated HOMO and LUMO and chemical potential $(\mu)$, electronegativity $(\chi)$, global hardness $(\eta)$, global softness $(S)$, global electrophilicity index $(\omega)$ and global nucleophilicity index $(\mathrm{E})$ of antiviral compounds by using the hybrid B3LYP level of theory.

\begin{tabular}{|c|c|c|c|c|c|c|c|}
\hline \multirow{3}{*}{ Orbits } & \multicolumn{6}{|c|}{ B3LYP/6-31G* } & \multirow{3}{*}{$\begin{array}{c}\text { 3-21G* } \\
\text { PCM } \\
\text { Idoxuridinef }\end{array}$} \\
\hline & \multirow{2}{*}{$\begin{array}{c}\text { PCM } \\
\text { Thymidinea }\end{array}$} & \multicolumn{2}{|c|}{ GAS PHASE } & \multirow{2}{*}{$\begin{array}{c}\text { PCM } \\
\text { Isothiazolc }\end{array}$} & \multirow{2}{*}{$\begin{array}{c}\text { PCM } \\
\text { Trifluridined }\end{array}$} & \multirow{2}{*}{$\begin{array}{c}\text { PCM } \\
\text { Emtricitabinee }\end{array}$} & \\
\hline & & Cidofovirb & Brincidofovirb & & & & \\
\hline HOMO & -6.2634 & -5.9366 & -5.5435 & -6.692 & -6.9621 & -6.1049 & -6.2613 \\
\hline LUMO & -0.8206 & -0.6401 & -1.7720 & -2.185 & -1.4443 & -1.0690 & -1.2703 \\
\hline $\mid$ GAP $\mid$ & -5.4428 & -5.2965 & -3.7715 & -4.507 & -5.5178 & -5.0359 & -4.991 \\
\hline \multicolumn{8}{|c|}{ DESCRIPTORS } \\
\hline$(\mathrm{eV})$ & Thymidinea & Cidofovirb & Brincidofovirb & Isothiazolc & Trifluridined & Emtricitabinee & Idoxuridinef \\
\hline$\chi$ & -2.7214 & -2.6483 & -1.8858 & -2.2535 & -2.7589 & -2.5598 & -2.4955 \\
\hline$\mu$ & -3.5420 & -3.2884 & -3.6578 & -4.4385 & -4.2032 & -3.6227 & -3.7658 \\
\hline$\eta$ & 2.7214 & 2.6483 & 1.8858 & 2.2535 & 2.7589 & 2.5598 & 2.4955 \\
\hline S & 0.1837 & 0.1888 & 0.2651 & 0.2219 & 0.1812 & 0.1953 & 0.2004 \\
\hline$\omega$ & 2.3050 & 2.0416 & 3.5474 & 4.3710 & 3.2018 & 2.5635 & 2.8414 \\
\hline $\mathrm{E}$ & -9.6392 & -8.7087 & -6.8979 & -10.0022 & -11.5962 & -9.2734 & -9.3976 \\
\hline
\end{tabular}


For thymidine and emtricitabine $[34,38,40]$ the results correspond to the C6 conformers, for trifluridine, C3 [35], for idoxuridine, C5 [36] while the isothiazole derivative correspond to 3-mercapto-5-phenyl-4-isothiazolecarbonitrile (I) [39]. For cidofovir, the most stable tautomer is the amino-oxo form which can be seen in Figure 3 together with the other structures compared. When these entire gap values are compared with those obtained for the species of foscarnet clearly it is observed that the most reactive antiviral species is the anhydrous salt of foscarnet and, then follow brincidofovir being the least reactive trifluridine in solution. Evidently, the presences of phosphate groups in their structures probably increase the activities of these compounds when they are used as drugs. On the other hand, emtricitabine is most reactive than trifluridine showing that the change of a $\mathrm{C}=\mathrm{O}$ group by an amine group with only an $\mathrm{F}$ atom increase the reactivity. When the descriptors are compared among them we observed the higher electrophilicty index for the isothiazole derivative and the low value for cidofovir while the higher nucleophilicity indexes are observed for trifluridine and the isothiazole derivative probably due to the CF3 and $\mathrm{C} \equiv \mathrm{N}$ groups present respectively in their structures. The low value of this latter index is observed for brincidofovir. In relation to the anhydrous species of foscarnet, we observed an electrophilicity index comparable to cidofovir and the isothiazole derivative while this antiviral salt evidences the lowest nucleophilicity index.

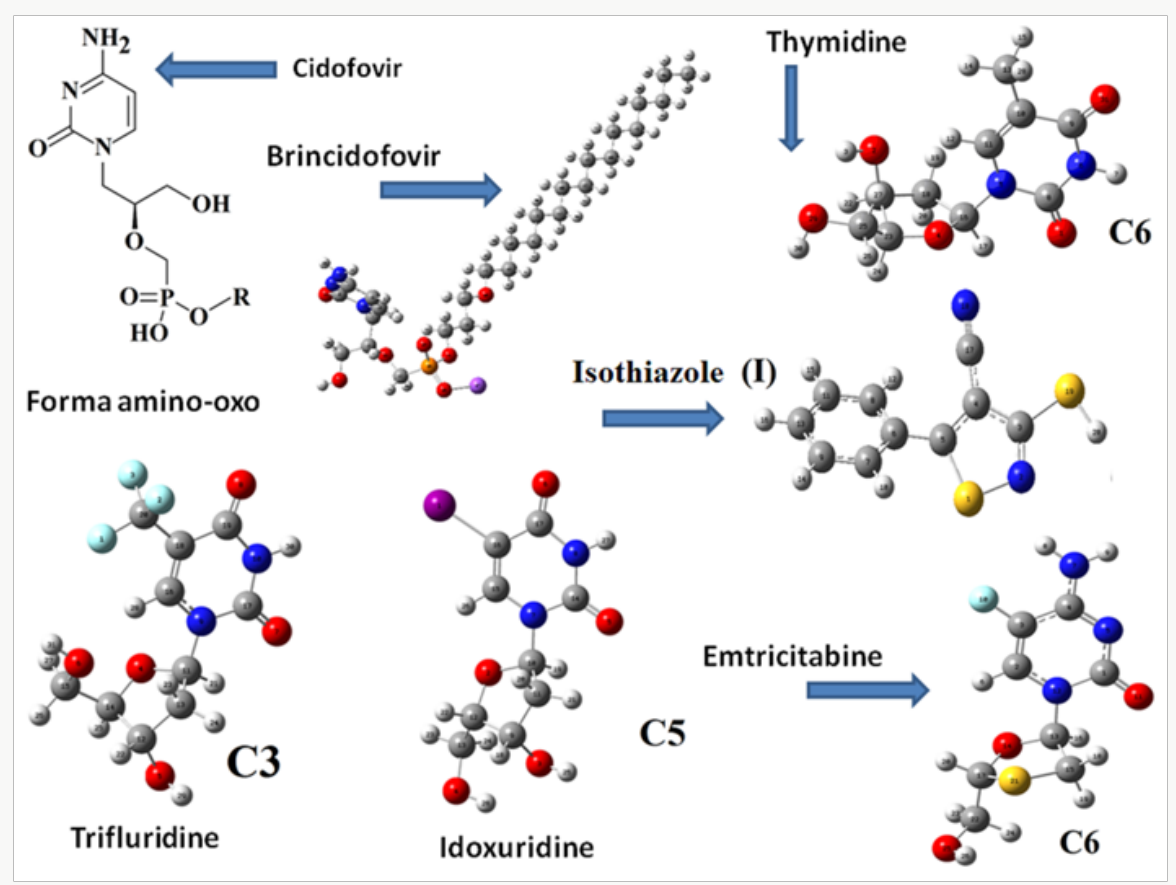

Figure 3: Molecular structures of antiviral compounds compared with the three species of foscarnet.

Table 12: Observed and calculated wave numbers ( $\mathrm{cm}-1)$ and assignments for the three studied species of foscarnet in gas and aqueous solution phases.

\begin{tabular}{|c|c|c|c|c|c|c|c|c|c|c|}
\hline $\operatorname{Exp}^{c}$ & $\begin{array}{l}\text { Acid } \\
\text { gas }^{\text {a }}\end{array}$ & Acid $\mathrm{PCM}^{\mathrm{a}}$ & $\begin{array}{l}\text { Salt } \\
\text { Gas }^{\text {a }}\end{array}$ & Salt PCMa & $\begin{array}{l}\text { Salt.6 } \\
\left(\mathrm{H}_{2} \mathrm{O}\right) \\
\text { PCMa }\end{array}$ & & & & & \\
\hline IR & $S Q M^{b}$ & Assig, ${ }^{a}$ & $\mathrm{SQM}^{\mathrm{b}}$ & Assig $^{\mathrm{a}}$ & $S_{Q} M^{b}$ & Assig $^{\mathrm{a}}$ & $S Q M^{b}$ & Assig $^{\mathrm{a}}$ & $S_{Q} M^{b}$ & Assig $^{\mathrm{a}}$ \\
\hline $3330 \mathrm{vs}$ & & & & & & & & & 3679 & $v_{\mathrm{a}} \mathrm{O}-\mathrm{H}(\mathrm{W} 5)$ \\
\hline \multirow[t]{2}{*}{$3231 \mathrm{vs}$} & 3691 & $\delta \mathrm{C} 5010 \mathrm{H7}$ & 3642 & $\delta \mathrm{C} 5010 \mathrm{H} 7$ & & & & & 3679 & $v_{a} \mathrm{O}-\mathrm{H}(\mathrm{W} 4)$ \\
\hline & 3670 & v 04-H9 & 3606 & v 03-H8 & & & & & 3678 & $v_{\mathrm{a}} \mathrm{O}-\mathrm{H}(\mathrm{W} 6)$ \\
\hline \multirow[t]{8}{*}{$2929 s$} & 3649 & v 03-H8 & 3595 & $v 04-\mathrm{H} 9$ & & & & & 3676 & $v_{a} \mathrm{O}-\mathrm{H}(\mathrm{W} 1)$ \\
\hline & & & & & & & & & 3672 & $v_{\mathrm{a}} \mathrm{O}-\mathrm{H}(\mathrm{W} 2)$ \\
\hline & & & & & & & & & 3671 & $v_{a} \mathrm{O}-\mathrm{H}(\mathrm{W} 3)$ \\
\hline & & & & & & & & & 3359 & CO-H(W6) \\
\hline & & & & & & & & & 3341 & $v_{s} \mathrm{O}-\mathrm{H}(\mathrm{W} 1)$ \\
\hline & & & & & & & & & 3322 & $v_{s} \mathrm{O}-\mathrm{H}(\mathrm{W} 5)$ \\
\hline & & & & & & & & & 3227 & $v_{s} \mathrm{O}-\mathrm{H}(\mathrm{W} 4)$ \\
\hline & & & & & & & & & 3095 & $v_{s} \mathrm{O}-\mathrm{H}(\mathrm{W} 2)$ \\
\hline
\end{tabular}




\begin{tabular}{|c|c|c|c|c|c|c|c|c|c|c|}
\hline & & & & & & & & & 3054 & $v_{s} \mathrm{O}-\mathrm{H}(\mathrm{W} 3)$ \\
\hline $2220 m$ & 2403 & $v \mathrm{P} 1-\mathrm{C} 5$ & 2401 & $v$ P1-C5 & 2091 & $v$ P1-C5 & 2295 & $v$ P1-C5 & & \\
\hline $1651 \mathrm{~s}$ & 1621 & $v_{\mathrm{a}} \mathrm{CO}_{2}$ & & & & & & & 1570 & $\delta \mathrm{O}-\mathrm{H}(\mathrm{W} 4)$ \\
\hline \multirow{3}{*}{$1633 \mathrm{~m}$} & & & & & & & & & 1561 & $\delta \mathrm{O}-\mathrm{H}(\mathrm{W} 2)$ \\
\hline & & & & & & & & & 1545 & $\delta 0-\mathrm{H}(\mathrm{W} 3)$ \\
\hline & & & & & & & & & 1542 & $\delta 0-H(W 5)$ \\
\hline \multirow[t]{2}{*}{$1553 \mathrm{~s}$} & & & 1543 & $v_{\mathrm{a}} \mathrm{CO}_{2}$ & & & & & 1527 & $\delta 0-\mathrm{H}(\mathrm{W} 1)$ \\
\hline & & & & & & & & & 1501 & $\delta 0-\mathrm{H}(\mathrm{W} 6)$ \\
\hline $1445 \mathrm{~m}$ & & & & & & & 1426 & $\mathrm{v}_{\mathrm{a}} \mathrm{CO}_{2}$ & 1444 & $v_{\mathrm{a}} \mathrm{CO}_{2}$ \\
\hline $1396 \mathrm{~s}$ & & & 1185 & $v$ 010-H7 & 1385 & $v_{\mathrm{a}} \mathrm{CO}_{2}$ & & & & \\
\hline $1333 v s$ & 1238 & $v \mathrm{aPO} 3$ & 1153 & $v_{\mathrm{a}} \mathrm{PO} 3$ & & & & & 1333 & $v_{s} \mathrm{CO}_{2}$ \\
\hline $1239 w$ & 1182 & $v 010-\mathrm{H} 7$ & 1054 & $\delta$ P103H8 & 1102 & $v_{\mathrm{a}} \mathrm{PO} 3$ & 1047 & $v_{\mathrm{s}} \mathrm{CO} 2$ & & \\
\hline \multirow[t]{2}{*}{ 1059vs } & 1019 & $\delta$ P104H9 & 1021 & $\delta$ P104H9 & 1060 & $v_{\mathrm{a}} \mathrm{PO3}$ & 1015 & $v_{a} \mathrm{PO} 3$ & 1032 & $v_{\mathrm{a}} \mathrm{PO}_{3}$ \\
\hline & 1002 & $\delta$ P103H8 & & & & & & & & \\
\hline $983 \mathrm{~s}$ & 966 & $v_{s} \mathrm{CO}_{2}$ & 947 & $v \mathrm{sCO}_{2}$ & 984 & $v_{s} \mathrm{CO}_{2}$ & 968 & $v_{a} \mathrm{PO3}$ & 969 & $v_{a} \mathrm{PO}_{3}$ \\
\hline 942sh & 864 & $v_{\mathrm{a}} \mathrm{PO}_{3}$ & & & 889 & $v_{s} \mathrm{PO}_{3}$ & 869 & $v_{s} \mathrm{PO} 3$ & 891 & $v_{s} \mathrm{PO}_{3}$ \\
\hline \multicolumn{11}{|l|}{$853 w$} \\
\hline $829 w$ & & & 831 & $v_{\mathrm{a}} \mathrm{PO3}$ & & & & & 820 & $\delta \mathrm{CO}_{2}$ \\
\hline \multirow[t]{3}{*}{$789 w$} & 795 & $v_{s} \mathrm{PO}_{3}$ & 800 & $v_{s} \mathrm{PO}_{3}$ & & & & & 815 & $\delta$ H18017H22 \\
\hline & & & & & & & & & 801 & $\begin{array}{c}\delta \text { 02H16014 } \\
\delta \mathrm{P} 102 \mathrm{H} 16\end{array}$ \\
\hline & & & & & & & & & 733 & $\begin{array}{c}\delta \mathrm{O} 2 \mathrm{H} 18017 \\
\delta 017 \mathrm{H} 22 \mathrm{O} 20 \\
\delta \mathrm{P} 102 \mathrm{H} 18\end{array}$ \\
\hline \multirow[t]{4}{*}{$718 w$} & & & & & & & & & 707 & $\delta 03 \mathrm{H} 12011$ \\
\hline & & & 682 & $\gamma \mathrm{CO}_{2}$ & 702 & $\delta \mathrm{CO}_{2}$ & 687 & $\gamma \mathrm{CO}_{2}$ & 697 & $\gamma \mathrm{CO}_{2}$ \\
\hline & & & & & 661 & $\gamma \mathrm{CO}_{2}$ & 663 & $\delta \mathrm{CO}_{2}$ & 666 & $\delta 04 \mathrm{H} 28026$ \\
\hline & 678 & $\gamma \mathrm{CO}_{2}$ & & & & & & & 655 & $\tau \mathrm{H}-\mathrm{O}$ \\
\hline \multicolumn{11}{|l|}{$\tau \mathrm{O}-\mathrm{H}$} \\
\hline & 561 & $\delta \mathrm{CO}_{2}$ & 551 & $\mathrm{CO}_{2}$ & & & & & 557 & $\delta \mathrm{sPO}_{3}$ \\
\hline & & & & & 530 & $\delta_{\mathrm{a}} \mathrm{PO}_{3}$ & & & & \\
\hline & 517 & $\tau \mathrm{C} 5-0$ & & & & & 511 & $\delta_{\mathrm{a}} \mathrm{PO}_{3}$ & 510 & $\begin{array}{c}\delta \mathrm{H} 16014 \mathrm{H} 24 \\
\delta \text { OHO }\end{array}$ \\
\hline & & & & & 500 & $\delta \mathrm{sPO}_{3}$ & & & 502 & $\delta \mathrm{aPO}_{3}$ \\
\hline & & & 493 & $\tau \mathrm{C} 5-0$ & & & & & 481 & $\begin{array}{c}\tau \mathrm{Na} 5-\mathrm{O} 20 \\
\tau \mathrm{O}-\mathrm{H}\end{array}$ \\
\hline & & & & & & & 462 & $\delta_{s} \mathrm{PO}_{3}$ & 471 & $\tau \mathrm{O}-\mathrm{H}$ \\
\hline & & & & & 448 & $\delta_{\mathrm{a}} \mathrm{PO}_{3}$ & & & 448 & $\tau \mathrm{O}-\mathrm{H}$ \\
\hline & 435 & $\delta_{\mathrm{a}} \mathrm{PO}_{3} \rho \mathrm{CO}_{2}$ & & & & & & & 435 & $\delta_{\mathrm{a}} \mathrm{PO}_{3}$ \\
\hline & & & 421 & $\rho \mathrm{CO}_{2}$ & 419 & $\rho \mathrm{CO}_{2}$ & 419 & $\delta_{\mathrm{a}} \mathrm{PO}_{3}$ & & \\
\hline & 388 & $\delta_{s} \mathrm{PO}_{3}$ & 397 & $\delta_{\mathrm{a}} \mathrm{PO}_{3}$ & & & 397 & $\rho \mathrm{CO}_{2}$ & 391 & $\tau \mathrm{Na5}-011$ \\
\hline & 381 & $\delta_{\mathrm{a}} \mathrm{PO}_{3}$ & 378 & $\delta_{s} \mathrm{PO}_{3}$ & 383 & 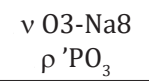 & & & 375 & $\rho \mathrm{CO}_{2}$ \\
\hline & & & & & & & & & 364 & v P1-C6 \\
\hline & & & & & & & & & 361 & $\delta \mathrm{H} 15014 \mathrm{H} 24$ \\
\hline & & & & & & & & & 359 & $\tau \mathrm{O}-\mathrm{H}$ \\
\hline & 334 & $\delta$ aP03 $\rho$ 'PO3 & 326 & $\delta \mathrm{aPO} 3$ & 325 & v 04-Na9 & & & & \\
\hline & & & 315 & $\tau \mathrm{P}-\mathrm{O}$ & & & 303 & $\rho$ 'P03 & 298 & $\tau \mathrm{Na} 5-\mathrm{O} 20$ \\
\hline & & & & & 287 & $\vee 010-\mathrm{Na} 7$ & & & 286 & $\begin{array}{c}\rho \mathrm{PO} 3 \\
\delta \mathrm{C} 608 \mathrm{Na} 9 \\
\nu \text { O7-Na10 } \\
\end{array}$ \\
\hline
\end{tabular}

Citation: Maximiliano A I, Silvia A B. Structural and Vibrational Study On the Acid, Hexa-Hydrated and Anhydrous Trisodic Salts of 


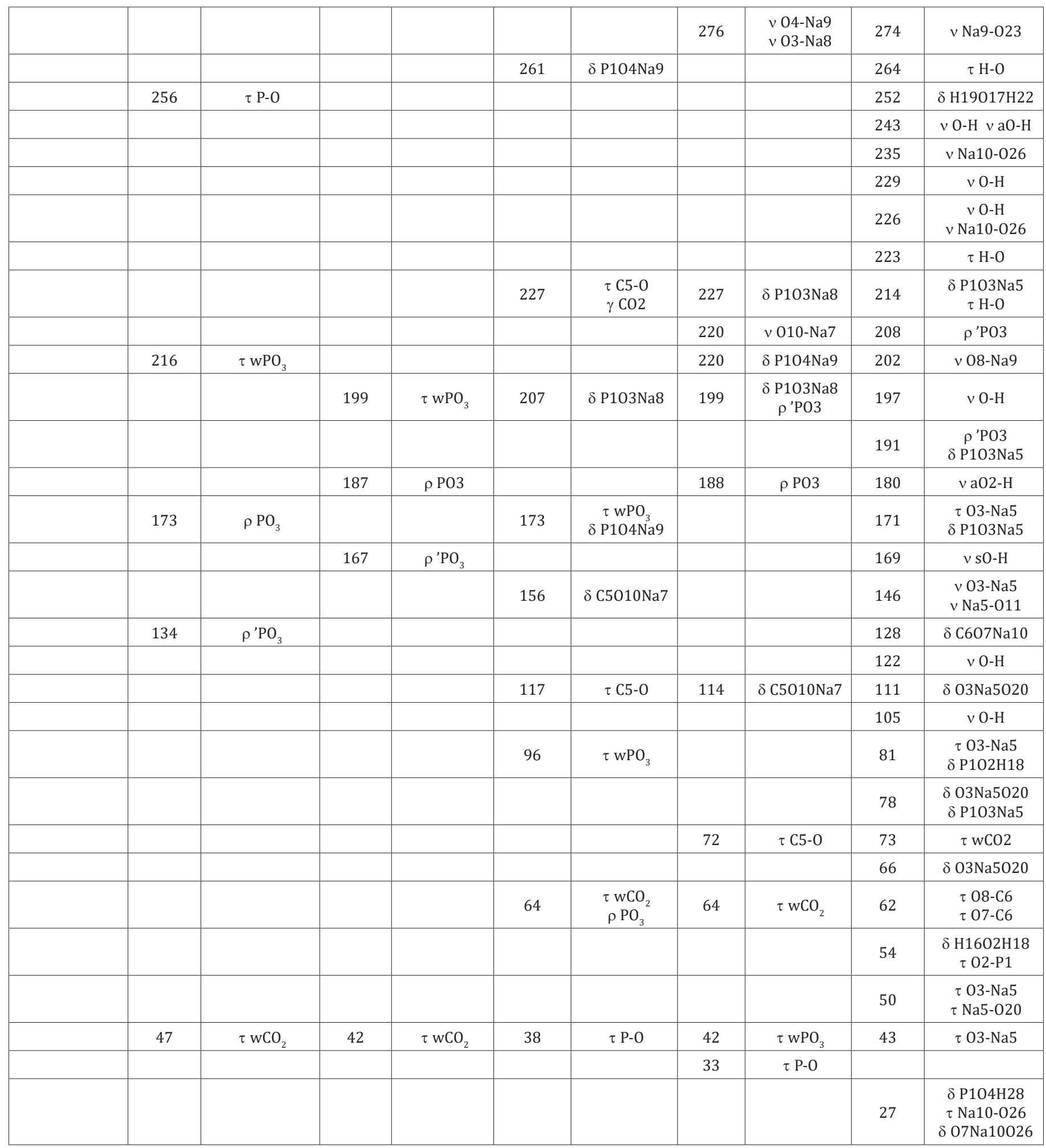

\section{Vibrational Analysis}

The acid species and the anhydrous salt present only 24 vibration modes while for the hexa hydrated species are expected 78 vibration modes where all their modes evidence activities in both infrared and Raman spectra because they are optimized with $\mathrm{C} 1$ symmetries. In Figure 4 is presented the experimental infrared spectrum of the hexa hydrated salt taken from Ref $[11,13]$ in the $4000-600 \mathrm{~cm}^{-1}$ region compared with the corresponding predicted in solution by using the B3LYP method and the $6-31 \mathrm{G}^{*}$ and $6-311++G^{* *}$ basis sets while in Figure 5 are compared the same spectra in the $2000-0 \mathrm{~cm}^{-1}$ region. The Raman spectrum predicted for the hydrated salt at the B3LYP/6-31G* level can be seen in Figure 6. The predicted IR spectra with both methods apparently show in all region a reasonable concordance with the corresponding experimental one (Figure 4) but when only the $2000-0 \mathrm{~cm}^{-1}$ region is considered are clearly observed four pairs bands in the 1750 - 
$1100 \mathrm{~cm}^{-1}$ and in $1100-1000 \mathrm{~cm}^{-1}$ where two of these latter bands (indicated with arrows in Figure 5) evidently are predicted separate by using the $6-311++G^{* *}$ basis set. Hence, the strong bands at 1059 and $983 \mathrm{~cm}-1$ are clearly associated to the phosphate group and are the typical bands used by different authors to identify foscarnet. In Table 12 are summarized the observed and calculated wave numbers and assignments for the three studied species of foscarnet in gas and aqueous solution phases. The assignments for the most important groups are presented below.

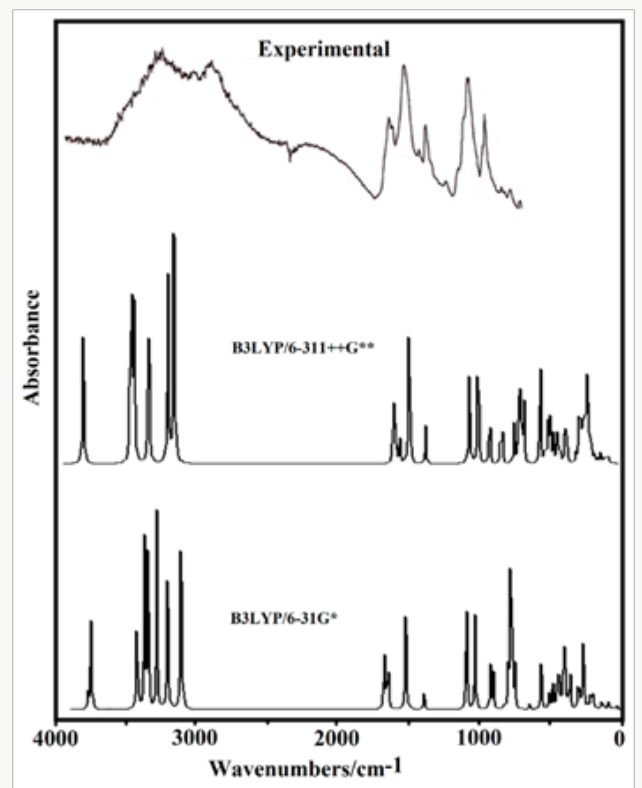

Figure 4: Experimental IR spectrum of the hexa hydrated salt taken from Ref $[11,13]$ in the $4000-600 \mathrm{~cm}-1$ region compared with the corresponding predicted in solution by using the B3LYP method and the $6-31 \mathrm{G}^{*}$ and $6-311++\mathrm{G}^{* *}$ basis sets.

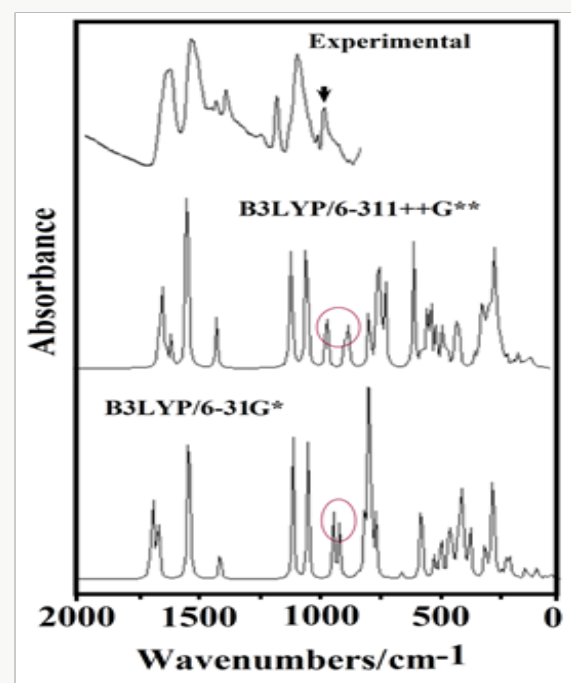

Figure 5: Experimental IR spectrum of the hexa hydrated salt taken from Ref [11,13] in the $2000-0 \mathrm{~cm}-1$ region compared with the corresponding predicted in solution by using the B3LYP method and the $6-31 \mathrm{G}^{*}$ and $6-311++\mathrm{G}^{* *}$ basis sets.

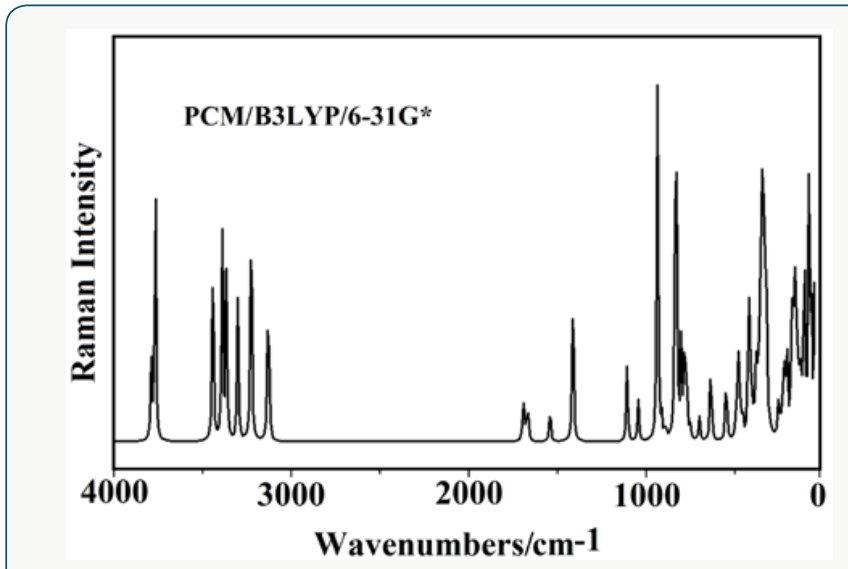

Figure 6: Predicted Raman spectrum for the hydrated salt at the B3LYP/6-31G* level of theory.

\section{Assignments}

Phosphate Groups: The symmetry of this group in a tetrahedral environment was considered $\mathrm{C} 3 \mathrm{v}$, as in similar compounds containing this group $[37,52]$. Hence, two anti symmetrical and a symmetrical mode are expected for this group, thus, these vibration modes are frequently assigned between 1175 and $954 \mathrm{~cm}^{-1}$ and, for this reason, the strong IR bands at 1059 and $983 \mathrm{~cm}-1$ are clearly assigned to those vibration modes for the hexa-hydrated species, as detailed in Table 12. However, note that in the acid these modes are predicted at 1238, 864 and $795 \mathrm{~cm}^{-1}$ while in the anhydrous salt they are assigned respectively at 1015,968 and $869 \mathrm{~cm}^{-1}$. In the lower wave number region are expected the deformation, wagging, rocking and twisting modes of this group, hence, the three deformation modes for the hydrated salt are predicted at 557, 502 and $435 \mathrm{~cm}^{-1}$ while the rocking modes at 208 and $191 \mathrm{~cm}^{-1}$. In the anhydrous salt the deformation modes are predicted between 530 and $419 \mathrm{~cm}^{-1}$ while in the acid 435 and $326 \mathrm{~cm}^{-1}$, thus, these modes are assigned in the regions predicted by SQM calculations. A very important observation, is that the P-C stretching modes in the hydrated species is predicted at $364 \mathrm{~cm}^{-1}$ while in the anhydrous salt and acid species they are predicted at 2403 and $2091 \mathrm{~cm}$ 1 , respectively. The strong shifting of this mode in the hydrated species could probably be justified by the six water molecules that are linked to the 0 atoms of phosphate group.

Carboxylate Groups: The asymmetric and symmetric stretching modes are usually assigned between 1772 and $1660 \mathrm{~cm}^{-1}$ [32-34,40,53]. Here, these vibration modes in the three species of foscarnet are predicted in different regions. Thus, in the hydrated salt those vibration modes are predicted at 1444 and $1333 \mathrm{~cm}^{-}$ ${ }^{1}$ while in anhydrous salt the SQM calculations predicted these modes in gas phase and in aqueous solution at 1385/984 and $1426 / 1047 \mathrm{~cm}^{-1}$, respectively. In the acid species, the asymmetric and symmetric stretching modes are predicted in the gas phase at $1621 / 966 \mathrm{~cm}^{-1}$ while in aqueous solution at 1543 and $947 \mathrm{~cm}^{-1}$. In both species, acid and anhydrous, is notable the shifting of these modes in solution, as a consequence of the hydration of these groups with water molecules. Obviously, these modes are assigned 
as predicted by calculations and, as reported in similar compounds [32-34,40,53]. The in-plane, out-of-plane deformation, rocking and twisting modes are normally assigned in the lower wave numbers region. Hence, in the hydrated species these modes are predicted respectively at $820,697,375$ and $73 \mathrm{~cm}^{-1}$ while in the anhydrous species at 702, 661, 419 and $6473 \mathrm{~cm}^{-1}$. In particular, in the acid species the out-of-plane deformation is predicted at higher wave numbers $\left(682 \mathrm{~cm}^{-1}\right)$ than the in-plane deformation $\left(551 \mathrm{~cm}^{-1}\right)$ while the rocking and twisting modes are predicted at 421 and $42 \mathrm{~cm}^{-1}$. Hence, these modes are assigned accordingly, as indicated in Table 12.

Water Vibrations: These vibration modes are predicted only for the hexa-hydrated species. The strong IR bands at 3330, 3231 and $2929 \mathrm{~cm}-1$ are obviously assigned to the anti symmetric and symmetric stretching modes expected for the $\mathrm{OH}$ groups of six water molecules while the three strong IR bands at 1651, 1633 and $1553 \mathrm{~cm}^{-1}$ are associated to the $\mathrm{OH}$ deformation modes of those six water molecules. The librations modes, such as waging, rocking and twisting modes related to the water molecules are expected in the lower wave numbers region, this way; the SQM calculations predicted those vibration modes from 655 up to $27 \mathrm{~cm}$ ${ }^{1}$, as observed in Table 12. Note that in this region also are observed other $\mathrm{OH}$ deformation modes related to the association of two water molecules and to the stretching and deformation modes associated to phosphate group linked to the water molecules.

Table 13: Comparison of scaled internal force constants for the three species of foscarnet in both media by using B3LYP/6$311++G^{* *}$ calculations

\begin{tabular}{|c|c|c|c|c|c|}
\hline \multicolumn{6}{|c|}{ B3LYP/6-311++G**a } \\
\hline & \multicolumn{2}{|c|}{ Acid } & \multicolumn{2}{|c|}{ Anhydrous } & \multirow{2}{*}{$\begin{array}{c}\text { Hydrated } \\
\text { PCM }\end{array}$} \\
\hline $\begin{array}{c}\text { Force } \\
\text { constant }\end{array}$ & Gas & PCM & Gas & PCM & \\
\hline $\mathrm{f}\left(v \mathrm{CO}_{2}\right)$ & 8.99 & 8.49 & 7.43 & 8.08 & 8.33 \\
\hline $\mathrm{f}\left(v \mathrm{PO}_{3}\right)$ & 6.40 & 6.17 & 6.77 & 5.13 & 6.55 \\
\hline $\mathrm{f}(v \mathrm{P}-\mathrm{C})$ & 2.55 & 2.54 & 2.09 & 2.45 & 2.60 \\
\hline $\mathrm{f}\left(\delta \mathrm{PO}_{3}\right)$ & 1.18 & 1.20 & 1.91 & 1.69 & 2.77 \\
\hline $\mathrm{f}\left(\delta \mathrm{CO}_{2}\right)$ & 1.19 & 1.14 & 2.22 & 1.72 & 1.95 \\
\hline
\end{tabular}

Force fields: For the acid and anhydrous and hexa-hydrated salts of foscarnet were calculated the force constants from the corresponding force fields in both media by using the SQM methodology and the Molvib program [26,27]. The values of these constants for the Carboxylate and phosphate groups are presented in Table 13. In general, it is observed that the acid and anhydrous salt show a slight decreasing in the force constants values in solution, as a consequence of the hydration, probably due to water molecules linked to the Carboxylate and phosphate hydration sites. On the other hand, the increase in the force constant value related to P-C bond in the anhydrous species could be attributed to the geometrical parameter because in gas phase present higher value than the corresponding in solution while the force constant value for the acid practically do not change in solution, in accordance with the value of its geometrical parameter. In the hydrated species, the predicted P-C distance in gas phase is $1.90 \AA$ while in solution decreases its value at $1.893 \AA$ and, this way, probably justify the shifting of this vibration mode towards lower wave numbers, as observed in the above section.

\section{Conclusions}

Here, the structural and vibrational properties of acid species, hexa-hydrated and anhydrous trisodic salts of antiviral drug foscarnet in gas phase and in aqueous solution were theoretically studied by using the hybrid B3LYP method with the 6-31G* and $6-311++G^{* *}$ basis sets. The properties in solution were studied with the self consistent reaction force (SCRF) method by using the integral equation formalism variant polarised continuum (IEFPCM) and SD models because these models consider the solvent effects. The complete vibrational assignments for those three species were performed in both media by using the experimental available infrared spectrum of hexa-hydrated trisodic salt and the scaled quantum mechanical force field (SQMFF) methodology. The NBO studies suggest that the hexa-hydrated salt in solution is most stable than the anhydrous in the same medium but in gas phase the anhydrous salt shows a higher stability in solution. The AIM analyses have revealed the ionic characteristics of the O---Na bonds in both salts supporting the higher stability of the hexa-hydrated salt in solution. The evaluation of the gap values by mean of the frontier orbital's show that the anhydrous salt is the most reactive species in solution, as supported by its higher solvation energy and volume variation. Apparently, the presences of phosphate group in foscarnet probably increase its activity when it is used as drug. The experimental infrared bands observed in the hexa-hydrated species at 1059 and $983 \mathrm{~cm}-1$ are clearly attributed to the stretching modes of phosphate group while the strong bands at 1445 and $1333 \mathrm{~cm}-1$ are associated to the stretching modes of carboxylate groups of the hexa-hydrated salt.

\section{Acknowledgement}

This work was supported with grants from CIUNT Project № 26/D207 (Consejo de Investigaciones, Universidad Nacional de Tucumán). The authors would like to thank Prof. Tom Sundius for his permission to use MOLVIB.

\section{Refernces}

1. Jan Sjovall, Anders Karlsson, Stephan Ogenstad, Sandström E, Saarimäki M (1988) Pharmacokinetics and absorption of foscarnet after intravenous and oral administration to patients with human immunodeficiency virus. Clin Pharmacol Ther 44(1): 65-73.

2. L Gérard, D Salmon Céron (1995) Pharmacology and clinical use of foscarnet. Int J Antimicrob Agents 5(4): 209-17.

3. Erik De Clercq (2004) Antiviral drugs in current clinical use. Journal of Clinical Virology 30(2): 115-133.

4. Jocelyne Piret, Guy Boivin (2011) Resistance of Herpes Simplex Viruses to Nucleoside Analogues: Mechanisms, Prevalence, and Management. Antimicrobial Agents and Chemotherapy 55(2): 459-472. 
5. G Zanetta, LM estepa, C Mousson, E Justrabo, M Daudon, et al. (1998) Foscarnet-Induced crystalline glomerulonephritis with nephritic syndrome and acute renal failure after kidney transplantation. Transplantation 67(10): 1376-1378.

6. Neil J Weiner, Jeffrey W Goodman, Paul L Kimmel (2003) The HIVassociated renal diseases: Current insight into pathogenesis and treatment. Kidney International 63(5): 1618-1631.

7. Michel Daudon, Paul Jungers (2004) Drug-Induced Renal Calculi. Epidemiology, Prevention and Management. Drugs 64(3): 245-275.

8. Arnaud Dessombz, Dominique Bazin, Paul Dumas, Christophe Sandt, Josep Sule-Suso, et al. (2011) Shedding Light on the Chemical Diversity of Ectopic Calcifications in Kidney Tissues: Diagnostic and Research Aspects. Plos One 6(11) e28007.

9. Bazin, Dominique, Daudon, Michel, Combes, Christèle, Rey Christian (2012) Characterization and Some Physicochemical Aspects of Pathological Micro calcifications. Chemical Reviews 112(10): 5092 5120.

10. M Daudon, D Bazin (2013) When the Synchrotron radiations highlight the Randall's plaques and kidney concretions. Journal of Physics: Conference Series 425022006.

11. D Bazin, C Jouanneau, S Bertazzo, C Sandt, A Dessombz, et al. (2016) Combining field effect scanning electron microscopy, deep UV fluorescence, Raman, classical and synchrotron radiation Fourier transform Infra-Red Spectroscopy in the study of crystal-containing kidney biopsies. CR Chimie 19(11-12): 1439-1450.

12. C Philipponnet, PA Michel, M Daudon, I Brocheriou, JJ Boffa (2015) Intravascular Foscarnet Crystal Precipitation Causing Multiorgan Failure. Am J Kidney Dis 65(1): 152-155.

13. V Frochot, D Bazin, E Letavernier, C Jouanneau, JP Haymann, M Daudon (2016) Nephrotoxicity induced by drugs: The case of foscarnet and atazanavird. A SEM and $\mu$ FTIR investigation. CR Chimie 19(11-12): 1565-1572.

14. Randell Mills, Guo Zhang Wu (2004) Synthesis and Evaluation of Novel Pro drugs of Foscarnet and Dideoxycytidine with a Universal Carrier Compound Comprising a Chem luminescent and a Photo chromic Conjugate. Journal OF Pharmaceutical Sciences 93(5): 1320-1336.

15. Boris Gorin, Colin G Ferguson, Gregory RJ Thatcher (1997) A Novel Esterification Procedure Applied to Synthesis of Biologically Active Esters of Foscarnet. Tetrahedron Letters 38(16): 2791-2794.

16. Jean Luc Maloisel, Brian G Pring, Anna Karin Tidén, Jeannette Dypbukt, Ewa Ljungdahl Ståhle, (1999) Neoglycolipid conjugates of foscarnet with enhanced antiviral activity in cells infected with human cytomegalovirus and herpes simplex virus type 1 . Antiviral Chemistry \& Chemotherapy $10(6): 333-345$.

17. C Meier, AM Aubertin, M de Monte, A Faraj, JP Sommadossr, et al. (1998) Synthesis and antiviral evaluation of SATE-foscarnet prodrugs and new foscarnet-AZT conjugates. Antiviral Chemistry \& Chemotherapy 9(1): 41-52.

18. Kaitlyn R Rouillard (2015) Synthesis of Fluorine Substituted Derivatives of a Bicyclic Aryl Sulfone as Potential Inhibitors of HHV-6 and HCMV Thesis. Georgia Regents University Augusta, Georgia.

19. Claudia Temperini, Alessio Innocenti, Annalisa Guerri, Andrea Scozzafava, Stefano Rusconib, et al. (2007) Phosph(on)ate as a zincbinding group in metalloenzyme inhibitors: X-ray crystal structure of the antiviral drug foscarnet complexed to human carbonic anhydrase I. Bioorganic \& Medicinal Chemistry Letters 17(8): 2210-2215.

20. Behzad Khalili, Mehdi Rimaz, Tahereh Tondro (2015) DFT study on foscarnet as an antiviral drug: Conformer analysis, gas phase acidity, metal ion affinity and influence of metal complexation on gas phase acidity. Journal of Molecular Structure 1080: 80-87.
21. AD Becke (1993) Density functional thermo chemistry. III. The role of exact exchange J Chem Phys 98: 5648-5652.

22. C Lee, W Yang, RG Parr (1988) Development of the Colle-Salvetti correlation-energy formula into a functional of the electron density. Phys Rev B37: 785-789.

23. S Miertus, E Scrocco, J Tomasi (1981) Electrostatic interaction of a solute with a continuum. A direct utilizaion of $\mathrm{AB}$ initio molecular potentials for the prevision of solvent effects. Chem Phys 55: 117-129.

24.J Tomasi, J Persico (1994) Molecular Interactions in Solution: An Overview of Methods Based on Continous Distributions of the Solvent. Chem Rev 94(7): 2027-2094.

25. AV Marenich, CJ Cramer, DG Truhlar (2009) Universal solvation model based on solute electron density and a continuum model of the solvent defined by the bulk dielectric constant and atomic surface tensions. J Phys Chem B 113(18): 6378-6396.

26. G Rauhut, P Pulay (1995) Transferable scaling factors for density functional derived vibrational force fields. J Phys Chem 99(10): 30933100

27. T Sundius (2002) Scaling of ab-initio force fields by MOLVIB. Vibrational Spectroscopy 29(1-2): 89-95.

28. RG Parr, RG Pearson (1983) Absolute hardness: companion parameter to absolute electro negativity. J Am Chem Soc 105(26): 7512-7516.

29. M Minteguiaga, E Dellacassa, MA Iramain, CAN Catalan, SA Brandán (2017) A structural and spectroscopic study on carquejol, a relevant constituent of the medicinal plant Baccharis trimera (Less.) DC. (Asteraceae). J Mol Struct 1150: 8-20.

30.F Chain, MF Ladetto, A Grau, CAN Catalán, SA Brandán (2016) Structural, electronic, topological and vibrational properties of a series of N-benzylamides derived from Maca (Lepidium meyenii) combining spectroscopic studies with ONION calculations. J Mol Struct 1105: 403414.

31. F Chain, E Romano, P Leyton, C Paipa, CAN Catalán, et al. (2015) Vibrational and structural study of onopordopicrin based on the FTIR spectrum and DFT calculations. Spectrochim Acta 150: 381-389.

32. F Chain, E Romano, P Leyton, C Paipa, CAN Catalán, MA Fortuna, SA Brandán (2014) An experimental study of the structural and vibrational properties of sesquiterpene lactone cnicin using FT-IR, FT-Raman, UVvisible and NMR spectroscopy's. J Mol Struct 1065-1066(1): 160-169.

33. FE Chain, P Leyton, C Paipa, M Fortuna, SA Brandán (2015) FT-IR, FTRaman, UV-Visible, and NMR spectroscopy and vibrational properties of the labdane-type diterpene 13-epi-sclareol, Spectrochim. Acta Part A 138: $303-313$.

34. Maria Belén Márquez, Silvia Antonia Brandán (2014) A structural and vibrational investigation on the antiviral deoxyribonucleoside thymidine agent in gas and aqueous solution phases. International J of Quantum Chem 114(3): 209-221.

35. Silvia Antonia Brandán (2017) Structural, topological, electronic and vibrational properties of the antiviral trifluridine agent. Their comparison with thymidine. Paripex A Indian Journal of Research 6(10): 346-360.

36. Davide Romani, Silvia Antonia Brandán (2017) Spectroscopic and Structural Study of the Antiviral Idoxuridine Agent by Using DFT and SCRF Calculations. IJSRM International Journal of Science And Research Methodology 8(1): 66-86.

37. Davide Romani, Silvia A Brandán (2015) Effect of the side chain on the properties from cidofovir to brincidofovir, an experimental antiviral drug against to Ebola virus disease. Arabian J Chem 1878-5352.

38. Davide Romani, Silvia Antonia Brandán (2017) Investigating the Structural and Vibrational Properties of the Nucleoside Reverse 
Transcriptase Inhibitor Emtricitabine. IJSRM International Journal of Science And Research Methodology 8(1): 236-277.

39. Davide Romani, María J Márquez, María B Márquez, Silvia A Brandán (2015) Structural, topological and vibrational properties of an isothiazole derivatives series with antiviral activities. J Mol Struct 1100: 279-289.

40. Maximiliano A Iramain, Ana E Ledesma, Davide Romani, Silvia Antonia Brandán (2017) Structural, electronic, topological and vibrational properties of isomers of thymidine-A study combining spectroscopic data with DFT calculations. IJSRM International Journal of Science and Research Methodology 8(2): 197-238.

41. AB Nielsen, AJ Holder (2008) Gauss View 5.0, User's Reference, GAUSSIAN Inc., Pittsburgh, PA.

42. HyperChem $®$ is a registered trademark of Hypercube, Inc.

43. AB Brizuela, MV Castillo, AB Raschi, L Davies, E Romano, SA Brandán (2014) A complete assignment of the vibrational spectra of sucrose in aqueous medium based on the SQM methodology and SCRF calculations. Carbohydrate Research 388: 112-124.

44. Te JA, Tan ML, Ichiye T (2010) Solvation of Glucose, Trehalose, and Sucrose by the Soft Sticky Dipole-Quadrupole-Octupole Water Model. Chem Phys Lett 491(4-6): 218-223.

45. MJ Frisch, GW Trucks, HB Schlegel, GE Scuseria, MA Robb, et al. (2009).

46. BH Besler, KM Merz Jr, PA Kollman (1990) Atomic charges derived from semi empirical methods. J Comp Chem 11: 431-439.
47. AE Reed, LA Curtis, F Weinhold (1988) Intermolecular interactions from a natural bond orbital, donor-acceptor viewpoint. Chem Rev 88(6): 899926.

48. ED Glendening, JK Badenhoop, AD Reed, JE Carpenter, F Weinhold (1996) NBO 3.1; Theoretical Chemistry Institute, University of Wisconsin, Madison, WI.

49. RFW Bader (1990) Atoms in Molecules. A Quantum Theory, Oxford University Press, USA.

50. F Biegler Köning, J Schönbohm, DJ Bayles (2001) AIM2000; A program to analyze and visualize atoms in molecules. Comput Chem 22(5): 545559 .

51. Ugliengo P (1998) MOLDRAW Program, University of Torino, Dipartimento Chimica IFM, Torino, Italy.

52. María L Roldán, Ana E Ledesma, Ana B Raschi, María V Castillo, Elida Romano, et al. (2013) A new experimental and theoretical investigation on the structures of aminoethyl phosphonic acid in aqueous medium based on the vibrational spectra and DFT calculations. J Molec Struct 1041: 73-81.

53. Fernando Chain, Maximiliano Alberto Iramain, Alfredo Grau, Cesar AN Catalán, Silvia Antonia Brandán (2017) Evaluation of the structural, electronic, topological and vibrational properties of $\mathrm{N}-(3,4-$ dimethoxybenzyl)-hexadecanamide isolated from Maca (Lepidium meyenii) using different spectroscopic techniques. J Molecular Structure 1123: 653-664.

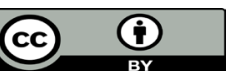

This work is licensed under Creative Commons Attribution 4.0 License

Submission Link:

Submit Article

DOI: $10.32474 /$ DDIPIJ.2018.01.000114

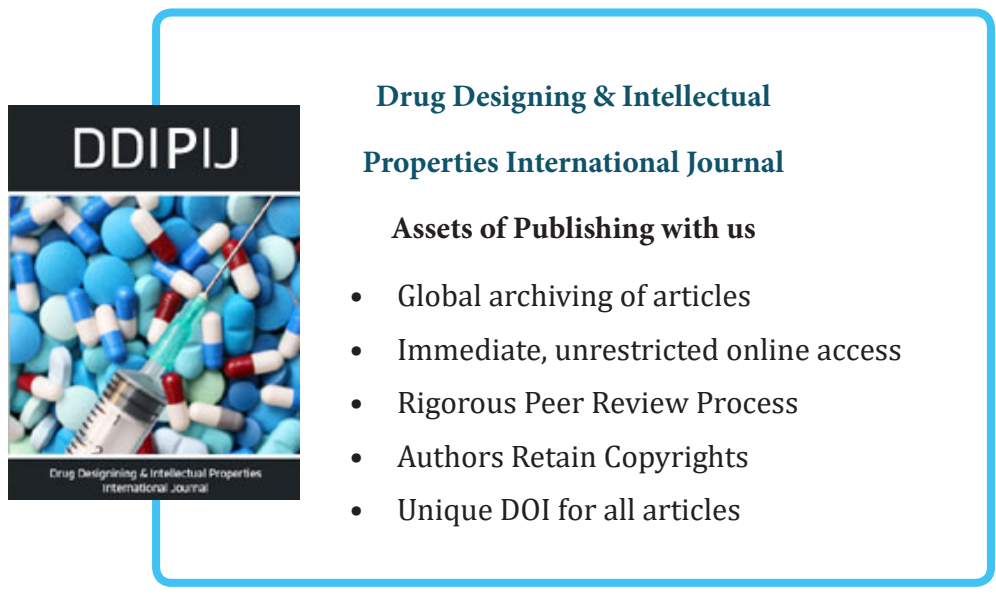

